\title{
Mesoporous silica nanoparticles functionalized with folic acid/methionine for active targeted delivery of docetaxel
}

This article was published in the following Dove Press journal:

OncoTargets and Therapy

I December 2016

Number of times this article has been viewed

\section{Pegah Khosravian' \\ Mehdi Shafiee Ardestani ${ }^{2}$ \\ Mehdi Khoobi ${ }^{3}$ \\ Seyed Naser Ostad ${ }^{4}$ \\ Farid Abedin Dorkoosh' \\ Hamid Akbari Javar ${ }^{1, *}$ \\ Massoud Amanlou, ${ }^{5,6, *}$ \\ 'Department of Pharmaceutics, ${ }^{2}$ Department of Radiopharmacy, \\ ${ }^{3}$ Department of Pharmaceutical \\ Biomaterials, ${ }^{4}$ Department of \\ Pharmacology and Toxicology, \\ ${ }^{5}$ Department of Medicinal \\ Chemistry, Faculty of Pharmacy and Pharmaceutical Sciences \\ Research Center, ${ }^{6}$ Drug Design and \\ Development Research Center, Tehran University of Medical Sciences, Tehran, Iran \\ *These authors contributed equally to this work}

Correspondence: Hamid Akbari Javar Department of Pharmaceutics, Faculty of Pharmacy, Tehran University of Medical Sciences, PO Box I4I55-645I, Tehran, Iran

Tel $+98912 \quad 1303177$

$\mathrm{Fax}+98216646 \quad 1178$

Email akbarijo@tums.ac.ir

Massoud Amanlou

Department of Medicinal Chemistry, Faculty of Pharmacy and Drug Design and Development Research Center, PO Box 14I55-645I, Tehran University of Medical Sciences, Tehran, Iran

Tel +98216 6959067

Fax+98216412 IIII

Email amanlou@tums.ac.ir

\begin{abstract}
Mesoporous silica nanoparticles (MSNs) are known as carriers with high loading capacity and large functionalizable surface area for target-directed delivery. In this study, a series of docetaxel-loaded folic acid- or methionine-functionalized mesoporous silica nanoparticles (DTX/MSN-FA or DTX/MSN-Met) with large pores and amine groups at inner pore surface properties were prepared. The results showed that the MSNs were successfully synthesized, having good pay load and $\mathrm{pH}$-sensitive drug release kinetics. The cellular investigation on MCF-7 cells showed better performance of cytotoxicity and cell apoptosis and an increase in cellular uptake of targeted nanoparticles. In vivo fluorescent imaging on healthy BALB/c mice proved that bare $\mathrm{MSN}_{-} \mathrm{NH}_{2}$ are mostly accumulated in the liver but MSN-FA or MSN-Met are more concentrated in the kidney. Importantly, ex vivo fluorescent images of tumor-induced $\mathrm{BALB} / \mathrm{c}$ mice organs revealed the ability of MSN-FA to reach the tumor tissues. In conclusion, DTX/MSNs exhibited a good anticancer activity and enhanced the possibility of targeted drug delivery for breast cancer.
\end{abstract}

Keywords: targeted delivery, mesoporous silica nanoparticle, folic acid, methionine, docetaxel

\section{Introduction}

Breast cancer is one of the most commonly diagnosed cancers among women, and its frequency has been shown to increase continuously. ${ }^{1,2}$ Although conventional chemotherapy methods could eliminate the majority of breast cancer cells, they are not always adequate and yet now breast cancer is one of the deadliest cancers. Unfortunately, traditional drug delivery systems for cancer therapy have numerous problems. One of the well-known problems is whole-body drug distribution before reaching cancer tissues, which in turn results in the use of high-dosage drugs and manifestation of serious toxic side effects. Therefore, it seems necessary to use new procedures for medicinal treatment. ${ }^{3,4}$ The use of nanoplatforms that contain specific ligands is becoming increasingly common to tackle the obstacles associated with conventional strategies. Nanoparticles accumulate in tumors with passive targeting effects, but particular ligands assist delivery systems to selectively recognize receptors at tumor cell surfaces and cause active targeted delivery.

As of now, several targeting agents, such as some types of recombinant proteins, vitamins, amino acids, and sugars, have been applied for active targeting in breast cancers. ${ }^{5}$ Identification of the best targeting agent for more effective and promising applications in the market should depend on stability, size uniformity, controlled release rate and large-scale manufacturing cost of fabricated nanoparticles. ${ }^{6}$ However, small 
targeting molecules are generally consumed in every cell and provide more uniform and stable nanodelivery systems with a greater chance to arrive at markets. Overexpression of folate receptors in breast cancer cells leads to specific uptake of nanoparticles that are conjugated with folate. Folic acid is a great putative marker and a target molecule for cancer diagnosis and therapy. ${ }^{7-10}$ Additionally, methionine (Met) is one of the essential amino acids and is a key factor in cell metabolism. ${ }^{11}$ Met is necessary for growth and differentiation of normal and the cancer cells. Therefore, tumor cells have a much greater requirement for Met than normal cells. ${ }^{12,13}$ Numerous lines of cancer cells such as MCF7 show Metdependent phenotypes that are unable to survive and grow when the amino acid, Met, is replaced with homocysteine precursors in the medium. ${ }^{14,15}$ Moreover, it was proven that the rate of Met transfer is increased in tumor cells by overexpressed LAT1 and LAT2 receptors. ${ }^{16-18}$ Therefore, inhibition of these carriers can suppress the growth of tumor cells. It may be concluded that Met may be used as a selective target for detection of tumor cells by Met-dependent phenotype. Therefore, Met as a targeting agent has been conjugated with some drug and imaging delivery systems for cancer therapy and tumor molecular imaging. ${ }^{19-21}$

A drug carrier requires to traverse through the cell membrane by favorable biophysical interaction with the lipid bilayer or by modifying lipids that resist movement of nanoparticles through lipid bilayers. ${ }^{22}$ A suitable drug carrier also needs to have some properties such as high drug-loading capacity, controlled drug release kinetics and target-directed distribution. ${ }^{23,24}$ Among these features for drug carriers, mesoporous silica nanoparticles (MSNs) exhibited some significant properties for targeted drug delivery such as controllable size and pore morphology, large inner and outer surface area to conjugate $\mathrm{pH}$-sensitive and targeting agents, high biocompatibility and selective release of cargo at the target region. ${ }^{25}$ Pore expansion, fabricated $\mathrm{pH}$-sensitive and targeting agents can endow MSNs with ideal properties to deliver their cargo toward cancerous cells. ${ }^{26-28}$

The aim of this study is to prepare MSN-Met or MSN-FA for active targeted delivery by improved MSNs that have large pores and $\mathrm{pH}$-sensitive release kinetic properties. Docetaxel (DTX), which is a potent anticancer drug and has wide usage in various cancers especially breast cancer, was used as a model hydrophobic anticancer drug. ${ }^{29-31}$ Prepared DTX/MSN-FA or DTX/MSN-Met were examined for their release profile in different $\mathrm{pH}$ conditions, and in vitro cellular tests such as intracellular uptake, cytotoxicity, and apoptosis were performed. To study the targeting abilities of these
MSNs, their biodistribution behavior was investigated in both healthy and tumor-induced BALB/c mice by in vivo and ex vivo fluorescence imaging.

\section{Materials and methods Materials}

Anhydrous DTX was purchased from Jiangsu Yew (Jiangsu, China). Cetyltrimethylammonium bromide (CTAB, 98\%), 3-aminopropyl triethoxysilane (APTS), mesitylene, hydroxybenzotriazole (HOBT), folic acid, methionine, fluorescein isothiocyanate (FITC) and MTT dye were purchased from Merck (Darmstadt, Germany). Tetraethyl orthosilicate (TEOS, 99\%), 1-ethyl-3-[3-(dimethylamino)propyl] carbodiimide (EDC), $N$-hydroxysuccinimide sodium salt (NHS) and 3a, 4, 5, 7a-tetrahydro-7-methyl-5(tetrahydro-2, 5-dioxo-3-furanyl)-1, 3-isobenzofurandione (Epiclon B-4400) were purchased from Sigma-Aldrich Co. (St Louis, MO, USA). Dulbecco's Modified Eagle's Medium (DMEM) with high glucose, RPMI 1640, fetal bovine serum (FBS), trypsin, L-glutamine, penicillin and streptomycin were purchased from Biosera (Vienna, Austria). Ultra-purified water was used throughout the analyses, and all other chemicals were of analytical grades. Human breast cancer cell line (MCF-7), rat breast cancer cell line (4T1) and BALB/c mice were obtained from Pasteur Institute of Iran (Tehran, Iran).

\section{Synthesis of MSNs and amine functionalization at inner and outer surfaces}

The multistep synthesis of large-pore and amine functional MSNs, by one-pot and co-condensation of TEOS and APTS, is schematically illustrated in Figure 1. First, an aqueous solution of CTAB $(1 \mathrm{~g})$ and $\mathrm{NaOH}(0.28 \mathrm{~g})$ was prepared with $480 \mathrm{~mL}$ of deionized water, ${ }^{24}$ and $7 \mathrm{~mL}$ of mesitylene was then added..$^{32}$ After 5 hours of high-speed stirring at $80^{\circ} \mathrm{C}$, TEOS $(5 \mathrm{~mL})$ and APTS $(0.21 \mathrm{~mL})$ were added dropwise into the solution, and the mixture was magnetically stirred for another 2 hours at the same temperature. ${ }^{33}$ The prepared MSNs were filtered and washed with deionized water and ethanol repeatedly. In the next step, MSNs (1 g) were redispersed in anhydrous ethanol $(100 \mathrm{~mL})$, and then APTS $(1 \mathrm{~mL})$ was added to the mixture gradually. ${ }^{34}$ The mixture was stirred for 12 hours and subsequently centrifuged at $5,000 \mathrm{rpm}$ for 25 minutes. The residue was washed several times with deionized water to remove unreacted APTS. Finally, $\mathrm{MSN}-\mathrm{NH}_{2}$ with amine groups at the inner and outer surfaces were dried under vacuum. 


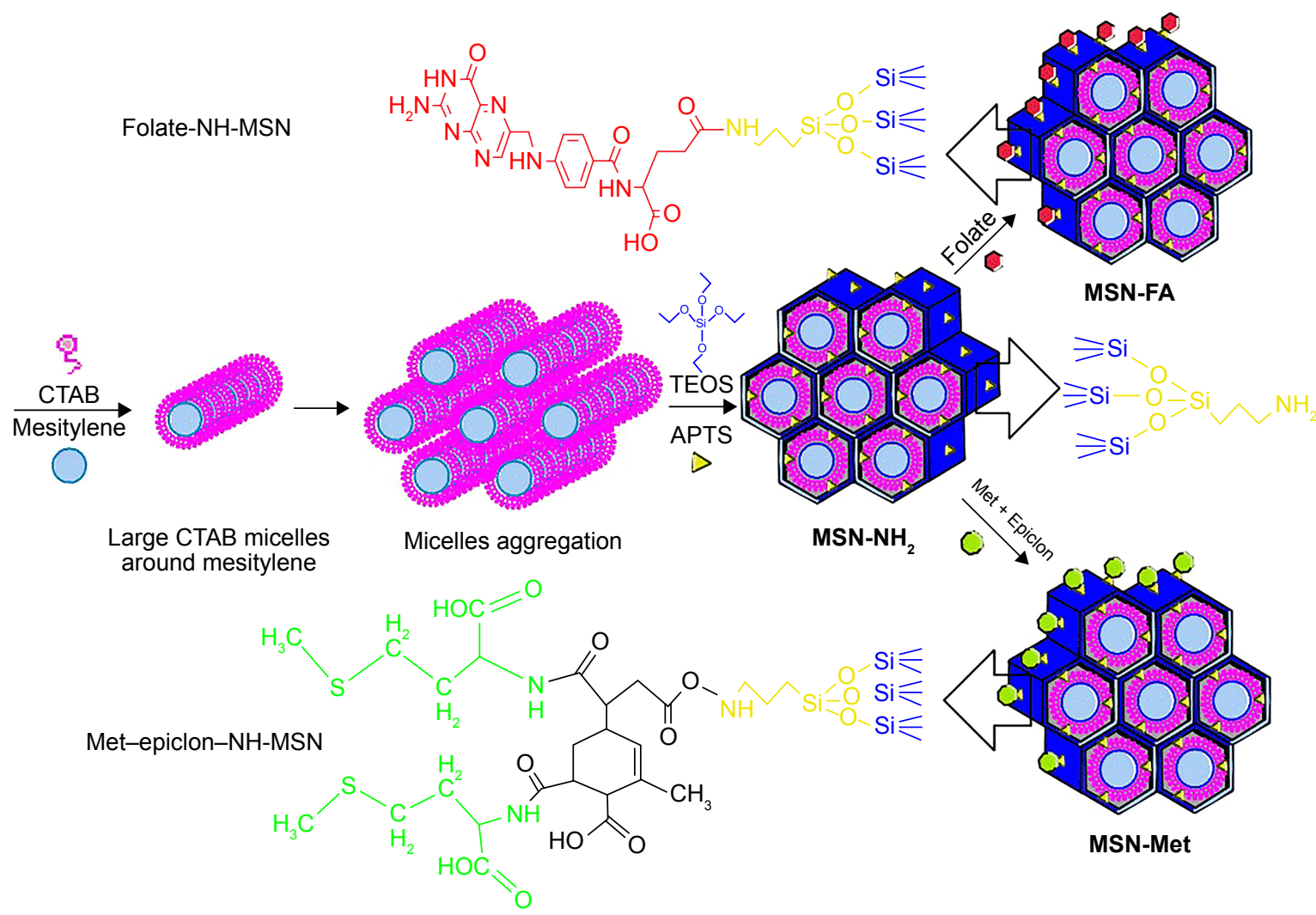

Figure I Schematic illustration of multistep synthesis of MSN-NH, MSN-FA, and MSN-Met.

Abbreviations: MSN, mesoporous silica nanoparticle; FA, folic acid; Met, methionine; CTAB, cetyltrimethylammonium bromide; TEOS, tetraethyl orthosilicate; APTS, 3-aminopropyl triethoxysilane.

\section{Synthesis of MSN-FA}

The $N$-hydroxysuccinimide ester of folic acid (NHS-folate) was initially prepared through esterification of folic acid $(1 \mathrm{mmol})$ with NHS $(1 \mathrm{mmol})$ in dry dimethylsulfoxide (DMSO, $0.4 \mathrm{~mL})$ solution of EDC ( $2 \mathrm{mmol})$ and HOBT $(1 \mathrm{mmol}) .{ }^{35}$ The mixture was stirred under $\mathrm{N}_{2}$ gas atmosphere for 30 minutes in an ice bath. Then, NHSfolate was added to the MSN-NH$H_{2}$ suspension $\left(\mathrm{MSN}-\mathrm{NH}_{2}\right.$ $0.1 \mathrm{mg}$, DMSO $4 \mathrm{~mL}$ ), and it was stirred under $\mathrm{N}_{2}$ gas atmosphere for 72 hours at room temperature. The mixture was washed with deionized water several times to produce MSN-FA (Figure 1).

\section{Synthesis of MSN-Met}

The surface of MSN-NH $\mathrm{N}_{2}$ was modified with Met and epiclon as a cross linker. To do so, a mixture of epiclon $(1 \mathrm{mmol})$ and L-Met $(2 \mathrm{mmol})$ in $5 \mathrm{~mL}$ of acetic acid was stirred at room temperature for 3 hours and then refluxed for 8 hours. The solvent was removed under vacuum, and a pale yellow precipitate was collected. ${ }^{36}$ This precipitate was used for MSN-NH ${ }_{2}$ modification via the same procedure used for preparation of folic acid-modified MSNs (Figure 1).

\section{Removing CTAB from MSNs}

CTAB was removed according to a previously reported procedure by simple modification. ${ }^{37}$ Briefly, a mixture of $\mathrm{NH}_{4} \mathrm{NO}_{3}(10 \mathrm{mg} / \mathrm{mL})$ and MSNs $(1 \mathrm{mg} / \mathrm{mL})$ was refluxed at $80^{\circ} \mathrm{C}$ for 6 hours under $\mathrm{N}_{2}$ gas atmosphere. The mixture was centrifuged at 20,000 rpm for 20 minutes and washed with deionized water several times. The procedure was repeated twice with renewal of $\mathrm{NH}_{4} \mathrm{NO}_{3}$ solution, and the removed MSNs were eventually obtained.

\section{Characterization of nanoparticles}

Different techniques were used to characterize prepared MSNs. The MSNs were tested by scanning electron microscopy (SEM) and transmission electron microscopy (TEM) techniques as well as Brunauer-Emmett-Teller (BET) and X-ray diffraction (XRD) analyses. SEM (FE-SEM, Tescan/ Mira, Brno, Czech Republic) was employed to determine the shape and surface morphology of MSNs. The nanoparticles were coated with gold under vacuum before analysis. TEM was carried out on a Zeiss EM10C, $80 \mathrm{KV}$, Germany, transmission electron microscope to closely observe MSN morphology. The surface area and pore size of MSNs were 
calculated by the BET and the Barrett-Joyner-Halenda (BJH) methods, respectively, on a $\mathrm{N}_{2}$ adsorption-desorption instrument (Quantachrome NOVA Automated Gas Sorption System, 2000e, USA). XRD patterns were collected on a STOE Theta-Theta Powder Diffraction System, STOE \& cie $\mathrm{GmbH}$, Germany. The presence of amorphous silica was analyzed from low-angle XRD pattern in the range of $2 \theta=0.5-8$. The surface composition of the nanoparticles at each step of surface modification was determined by infrared (IR) spectra. IR spectra were recorded on a Nicolet Magna IR-550, USA, using KBr pellets.

Thermal gravimetric analysis (TGA) curves were collected with a TGA STA PT 1600, Linseis, Germany, with a temperature ramp of $5^{\circ} \mathrm{C} / \mathrm{min}$ or $10^{\circ} \mathrm{C} / \mathrm{min}$ for the MSNs. The system was purged under $\mathrm{N}_{2}$ atmosphere with a rate of $50 \mathrm{~mL} / \mathrm{min}$. The particle size, size distribution, and zeta potential measurements of the MSNs were taken by dynamic light scattering (DLS; ZEN3600 Zetasizer; Malvern Instruments, Malvern, UK). The surface elements of MSNMet were determined by energy dispersive X-ray analysis (EDAX) with a scanning electron microscope (FE-SEM, Tescan/Mira) coupled with an EDAX detector. EDAX spectrum was measured at $20 \mathrm{kV}$ accelerating voltage.

\section{Drug entrapping and in vitro release}

For drug loading, $50 \mathrm{mg}$ of $\mathrm{MSN}_{-\mathrm{NH}_{2}}$, MSN-FA, or MSNMet were soaked in $5 \mathrm{~mL}$ of DTX solution in methanol (50 mg/mL). After stirring for 24 hours under light-sealed conditions, the DTX-loaded MSNs were centrifuged and washed with $20 \mathrm{~mL}$ of methanol. To evaluate the DTX loading efficiency, the supernatant was collected, and the residual DTX content was determined by a UV-Vis spectrophotometer at $229.5 \mathrm{~nm} .{ }^{38}$ The loading efficiency and loading capacity of DTX were calculated by Equations 1 and 2, respectively:

$\%$ Loading efficiency
$=\frac{\text { Initial amount of DTX }- \text { Amount of DTX in supernatant }}{\text { Initial amount of DTX }} \times 100$

\% Loading capacity

$=\frac{\text { Initial amount of DTX }- \text { Amount of DTX in supernatant }}{\text { Amount of DTX- loaded nanoparticles }} \times 100$

DTX release from drug-loaded MSNs was determined in two phosphate-buffered saline (PBS) media with $\mathrm{pH}$ values of 5.2 and 7.4 to simulate normal and tumor environments. Due to the poor aqueous solubility of DTX, Tween 80
$(0.1 \% \mathrm{w} / \mathrm{v})$ was added to the release medium to create the sink condition. Briefly, the $10 \mathrm{mg}$ DTX-MSNs were dispersed in both media. These MSN dispersions were shaken at $37^{\circ} \mathrm{C}$ with a speed of $100 \mathrm{rpm}$ under a light-sealed condition. At a predetermined sampling time, the suspension was centrifuged at 17,000 rpm for 10 minutes, and then, the supernatant was separated. Moreover, the MSNs were resuspended by adding adequate amounts of fresh media in order to continue the release profile, while maintaining the sink condition. Additionally, DTX quantities of the supernatant were determined by high-performance liquid chromatography and were based on the calibration curve after filtration through a $0.22 \mu \mathrm{m}$ membrane filter. ${ }^{39}$

\section{MSN-NH${ }_{2}$, MSN-FA, and MSN-Met labeling}

To label MSN-NH, MSN-FA, and MSN-Met, FITC was connected to their amine groups. A solution of $1 \mathrm{~mL}$ FITC $(0.1 \mathrm{mg} / \mathrm{mL})$ in acetonitrile was added to $10 \mathrm{mg}$ of the particles, and it was stirred at room temperature in darkness for 2 hours. ${ }^{40}$ The modified MSNs were collected by centrifugation. After three times of washing, the FITC-MSNs were dried under vacuum and used for cellular and animal tests.

\section{Cellular uptake}

To reveal cellular uptake efficiency of FITC-MSNs, MCF-7 cells were seeded in 6-well plates with a density of $2 \times 10^{5}$ cells per well and incubated at $37^{\circ} \mathrm{C}$ in the presence of $5 \% \mathrm{CO}_{2}$ for 24 hours. FITC-MSNs $(100 \mu \mathrm{M})$ and FITC (negative control) were added to each well, and cells were incubated at $37^{\circ} \mathrm{C}$ and $5 \% \mathrm{CO}_{2}$ for 2 hours. The culture medium was removed, and cells were softly rinsed twice with PBS. At last, the cells were analyzed using a BD FACSCalibur four-color analysis cytometer (BD Biosciences, San Jose, CA, USA), and data were analyzed with WinMDI 2.9 Software.

\section{Cellular cytotoxicity}

In vitro cytotoxicity of MSN-NH ${ }_{2}, \mathrm{MSN}-\mathrm{FA}$, and MSN-Met containing DTX compared to that of free DTX and biocompatibility of drug-free MSNs were determined using the MTT assay. The cells were cultured in RPMI 1640, containing $10 \% \mathrm{FBS}$ at $37^{\circ} \mathrm{C}$ in a humidified and $5 \% \mathrm{CO}_{2}$ incubator. Then, MCF-7 cells $\left(1 \times 10^{4}\right)$ were cultured in a 96 -well plate with $100 \mu \mathrm{L}$ of growth medium per well. For treatment, free DTX stock solution was prepared in the growth medium (containing 0.1\% DMSO) and was further serially diluted with the growth medium. Different dilutions of DTX-loaded MSNs were prepared with the same DTX concentration as for free DTX. Cells were incubated for 24 hours, 48 hours 
and 72 hours, and then $20 \mu \mathrm{L}$ of MTT solution $(5 \mathrm{mg} / \mathrm{mL})$ was added to each well. After cells were incubated for another 4 hours, they were centrifuged and $100 \mu \mathrm{L}$ of DMSO was added to each well. Supernatant was gathered, and the absorbance was monitored at $570 \mathrm{~nm}$ on a microplate ELISA reader (BIOHIT, Finland). ${ }^{41}$

\section{Evaluation of MCF-7 cell death mechanisms}

Annexin V-FITC apoptosis detection kit (Thermo Fisher Scientific, Waltham, MA, USA) was used to quantify the apoptotic and necrotic cells by a standard fluorescenceactivated cell sorting (FACS) assay. First, MCF-7 cells were seeded into 6-well plates $\left(2 \times 10^{6}\right.$ cells per well). After incubation for 24 hours, cells were treated with $100 \mu \mathrm{L}$ of Hank's buffer solution containing DTX (positive control) or DTX/ MSNs (40 nM) with the same drug concentration at $\mathrm{pH} 7.4$. At the end of the incubation ( 24 hours), the culture medium was discarded, and cells were washed twice with the Hank's solution. After monolayer trypsinization, the FITC-labeled Annexin V was added to each well. Cells were incubated at room temperature on the shaker $(100 \mathrm{rpm})$ for 15 minutes in darkness. In the next step, the PI stock solution was added to each well. Finally, cells were incubated for another 5 minutes and washed twice with the Hank's solution again. Cytometric analyses were carried out on FACSCalibur analysis cytometer by WinMDI 2.9 Software. Throughout early apoptosis, phosphatidylserine (PS) was translocated from the inner to the outer membrane surface. Then, cells with accessible PS were stained with Annexin V. Consequently, propidium iodide (PI) was used for identification of early and late apoptotic cells. Viable cells with undamaged membranes excluded PI, whereas the membranes of dead and damaged cells were permeable to PI. ${ }^{42,43}$ Therefore, cytometric analyses by FACSCalibur were represented of living cells (stained negative for both Annexin V and PI) at lower left quadrant, early apoptotic cells (stained positive for Annexin V and negative for PI) at lower right quadrant, late apoptotic cells at upper right quadrant (stained positive for both Annexin V and PI) and necrotic cells (stained positive for PI) at upper left quadrant. ${ }^{44}$

\section{Tumor model handling}

To develop 4T1 breast tumor model in BALB/c mice, 4T1 cells were cultured in DMEM medium containing 10\% FBS, $0.03 \%$ L-glutamine, $100 \mathrm{U} / \mathrm{mL}$ penicillin and $100 \mathrm{mg} / \mathrm{mL}$ streptomycin at $37^{\circ} \mathrm{C}$ and $5 \% \mathrm{CO}_{2}$. The murine cells were trypsinized and resuspended in the culture medium. After centrifugation, cells were resuspended in a serum-free medium, and $1 \times 10^{6}$ cells were injected in the left flank of BALB/c mice under ketamine and xylazine anesthesia. Tumor growth was visible $2-3$ weeks postinjection. ${ }^{45}$

\section{In vivo and ex vivo fluorescence imaging}

An optical imaging system (F PRO, Kodak, US) was used for in vivo and ex vivo fluorescence imaging, and the excitation and emission wavelengths were set at $495 \mathrm{~nm}$ and $519 \mathrm{~nm}$, respectively. In vivo fluorescence imaging was used to observe the real-time distribution of MSNs in healthy BALB/c mice to obtain highly visible intensity and find the proper time for the next stage of the biodistribution study by dissecting the mice organs. Briefly, BALB/c mice were treated with a single dose within heart injection of FITC-MSN-NH ${ }_{2}$, FITC-MSN-FA, FITC-MSN-Met or PBS (control) on triple groups. The near infrared (NIR) fluorescent images were obtained at 0.5 hour, 1 hour, 2 hours, 4 hours, 8 hours and 24 hours after injection of $0.2 \mathrm{~mL}$ of nanoparticles $(10 \mathrm{mg} / \mathrm{mL})$ by Kodak in vivo imaging system. At the best intensity time, the study was conducted on scarified organs of both healthy and tumor-induced BALB/c mice. Kodak Molecular Imaging Software 5.X was employed for fluorescence image analysis of each organ and tumor tissue in both healthy and tumor-induced BALB/c mice. Ethics approval for the study was obtained from the Ethics Committee of Tehran University of Medical Sciences. All animal-handling procedures were performed according to the Guide for the Care and Use of Laboratory Animals of the Tehran University of Medical Sciences (purchase, transportation, maintenance and slaughter) and followed the guidelines of the Animal Welfare Act and Declaration of Helsinki.

\section{Statistical analysis}

The results were expressed as mean \pm SD. The significance of differences between groups was determined via two-way analysis of variance followed by the Newman-Keuls multiple comparison tests. Differences were considered significant at $P<0.05$. All statistics were conducted using GraphPad Prism 6.01 (GraphPad Software, La Jolla, CA, USA) for Windows.

\section{Results and discussion Characterization of nanoparticles}

According to the SEM image of $\mathrm{MSN}-\mathrm{NH}_{2}$, samples were found to be uniform with a good dispersion and spherical shape ( $\sim 50 \mathrm{~nm}$ in diameter), which was also revealed by TEM image (Figure 2A and B). Mesoporous structure of MCM-41 could also be confirmed with nanochannels of $\mathrm{MSN}^{-\mathrm{NH}_{2}}$ in the TEM image. ${ }^{46}$

The synthesized $\mathrm{MSN}-\mathrm{NH}_{2}$ exhibited an average diameter of $49 \mathrm{~nm}$ with a narrow size distribution (polydispersity index $=0.222$; Figure 2E). As DLS measures hydrodynamic 
A

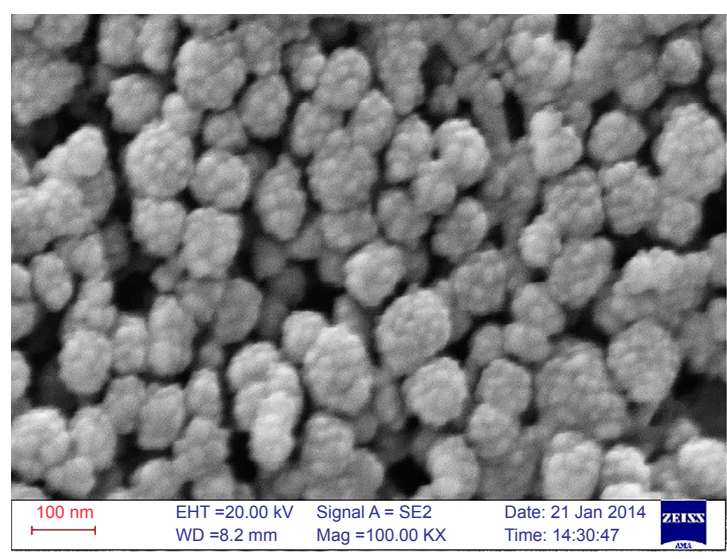

C

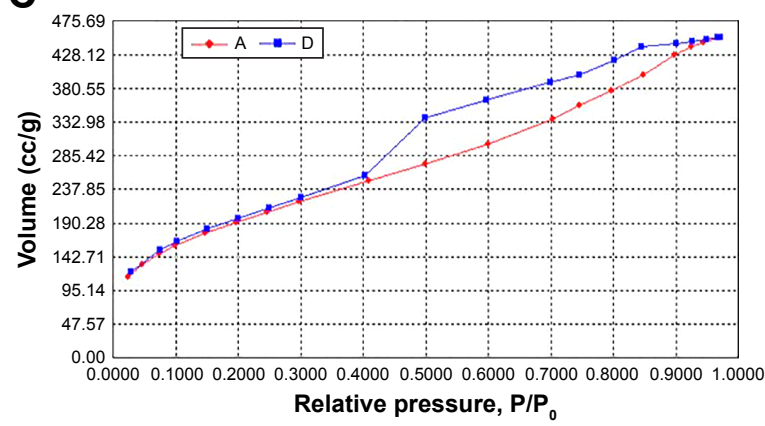

$\mathbf{E}$

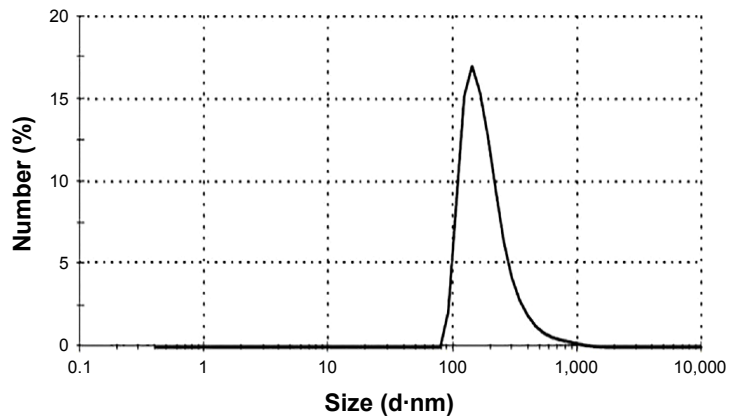

B

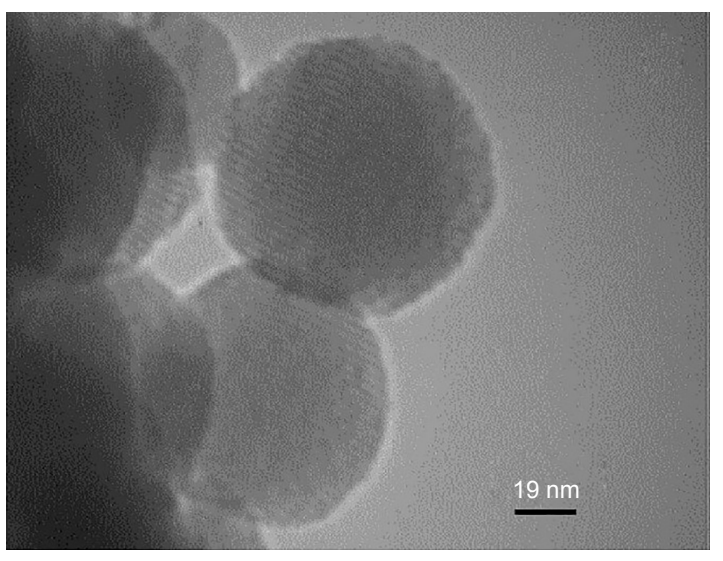

D

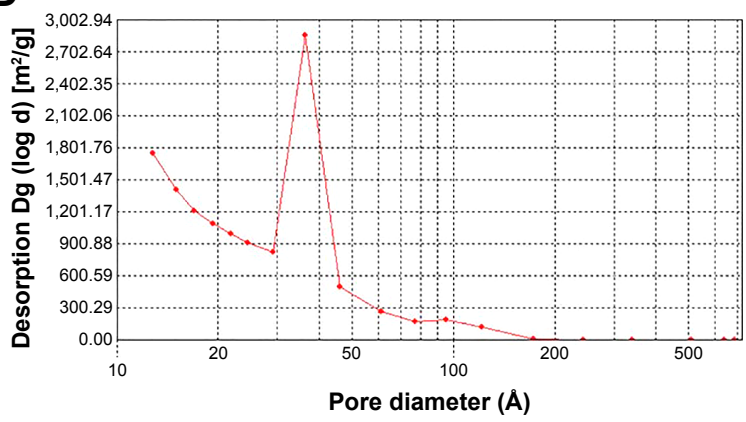

$\mathbf{F}$

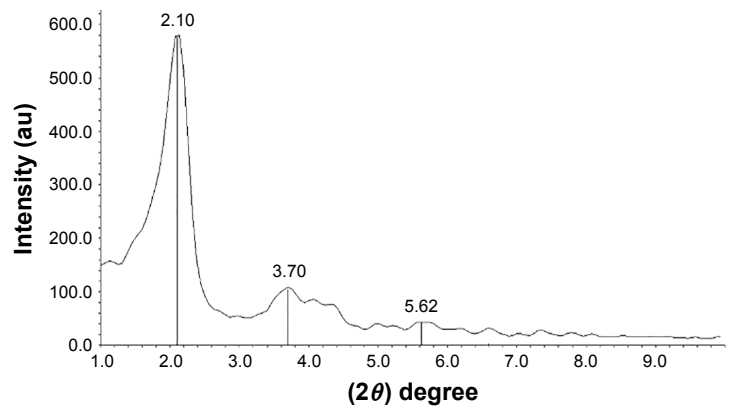

Figure 2 Representative of SEM and TEM images, nitrogen adsorption/desorption isotherm, $\mathrm{BJH}$ size distribution plots, and XRD pattern of MSN-NH .

Notes: (A) SEM image, (B) TEM image, (C) nitrogen adsorption/desorption isotherm, (D) BJH pore size distribution, (E) size distribution by number from DLS method, and $(\mathbf{F})$ low-angle XRD pattern of $\mathrm{MSN}^{-\mathrm{NH}_{2} \text {. }}$

Abbreviations: SEM, scanning electron microscopy; TEM, transmission electron microscopy; BJH, Barrett-Joyner-Halenda; DLS, dynamic light scattering; XRD, X-ray diffraction; MSN, mesoporous silica nanoparticle.

diameter, ${ }^{47,48}$ the larger size was observed by DLS method in Figure 2E. DLS analysis of obtained MSNs showed satisfactory dispersion for cellular and animal tests.

The formation of a mesoporous structure was confirmed by BET analysis. Nitrogen adsorption/desorption isotherm of $\mathrm{MSN}-\mathrm{NH}_{2}$ showed a typical type IV isotherm ${ }^{49}$ with a narrow hysteresis loop, and the $\sim 700 \mathrm{~m}^{2} / \mathrm{g}$ of $\mathrm{MSN}_{-} \mathrm{NH}_{2}$ revealed the highest BET surface area (Figure 2C). BJH pore size distribution is depicted in Figure 2D. Average pore diameters of $3.8 \mathrm{~nm}$ were obtained for $\mathrm{MSN}-\mathrm{NH}_{2}$, showing the fact that mesitylene was attributed to micelle composition and generated bigger pore sizes.
XRD analysis of MSN-NH${ }_{2}$ showed the pattern that is typical for mesoporous materials. ${ }^{49}$ The pattern at low-angle XRD demonstrated three main diffraction peaks at 2.1, 3.7, and 5.62 related to the (100), (110), and (200) lattice planes, respectively (Figure $2 \mathrm{~F}$ ).

The Fourier transformed infrared spectroscopy (FTIR) spectra of the MSNs confirmed modification of the MSNs with different functional groups. Figure 3 exhibits FTIR spectra of MSN-NH$H_{2}, \mathrm{MSN}-\mathrm{Met}$, and MSN-FA. The strong peaks appeared at around 1,080, 950, and $800 \mathrm{~cm}^{-1}$ are due to the stretching vibration of $\mathrm{Si}-\mathrm{O}-\mathrm{Si}, \mathrm{Si}-\mathrm{OH}$, and $\mathrm{Si}-\mathrm{O}$, respectively, which are specific peaks of the silica 


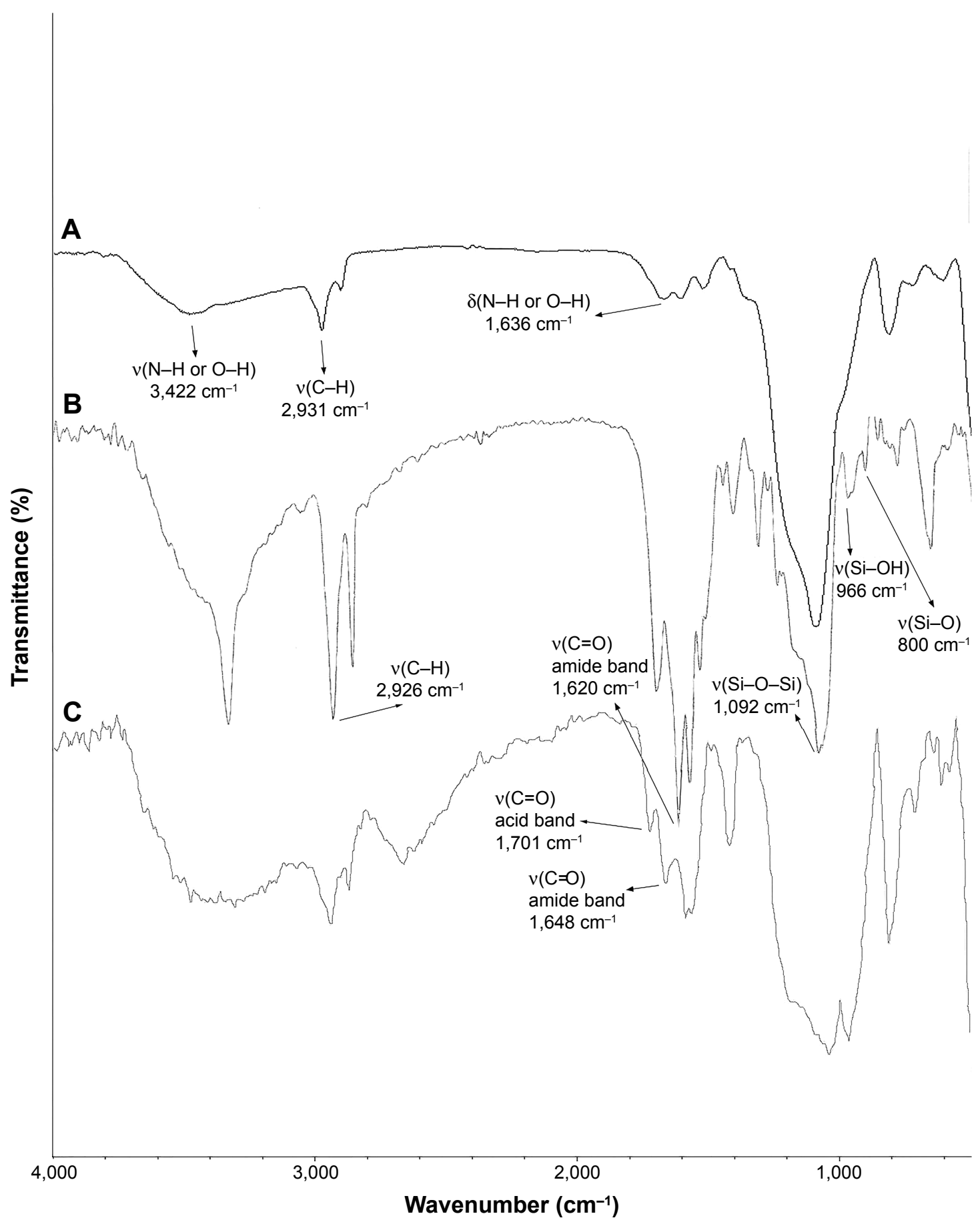

Figure 3 FTIR spectra of (A) MSN-NH ${ }_{2}$, (B) MSN-FA, and (C) MSN-Met.

Abbreviations: FTIR, Fourier transformed infrared spectroscopy; MSN, mesoporous silica nanoparticle; FA, folic acid; Met, methionine.

nanoparticles, and the broad band around $3,400 \mathrm{~cm}^{-1}$ can be attributed to the $\mathrm{N}-\mathrm{H}$ or $\mathrm{O}-\mathrm{H}$ groups. The band appeared at around $1,600 \mathrm{~cm}^{-1}$ is ascribed to the bending vibration of $\mathrm{O}-\mathrm{H}$ or $\mathrm{N}-\mathrm{H}$. Additionally, the bands at about $2,900 \mathrm{~cm}^{-1}$ correspond to the $\mathrm{C}-\mathrm{H}$ stretching vibration of amino propyl groups. The appearance of a peak at about $1,620-1,650 \mathrm{~cm}^{-1}$ could be attributed to the formation of amide bands after
MSN-NH ${ }_{2}$ modification with folate or epiclon-Met. The stretching vibration at around $1,700 \mathrm{~cm}^{-1}$ implies the presence of acid groups of epiclon (Figure 3).

Zeta potentials demonstrated surface modifications of MSNs. The amine functionalization caused changes in zeta potential for $\mathrm{MSN}_{-} \mathrm{NH}_{2}$ (+5.9). Also, positively charged folate conjugation increased the zeta potential of MSN-FA 


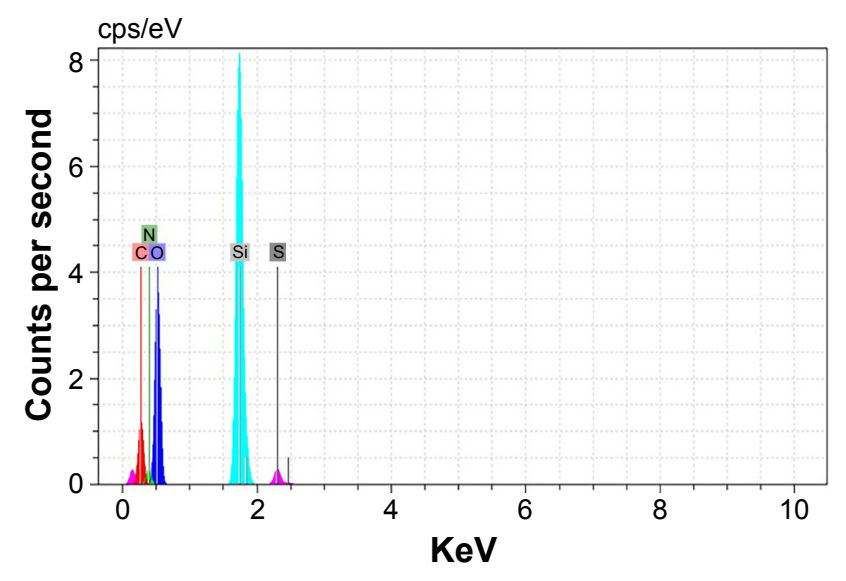

Figure 4 EDAX spectra obtained of MSN-Met.

Abbreviations: EDAX, energy dispersive $X$-ray analysis; MSN, mesoporous silica nanoparticle; Met, methionine; C, carbon; N, nitrogen; O, oxygen; Si, silicon; S, sulfur.

to $+8.11 \mathrm{mV}$. Surface modification with negatively charged epiclon-Met was confirmed by decreasing the zeta potential of the MSN-Met to $-5.65 \mathrm{mV}$.

The surface composition of MSN-Met was qualitatively determined by energy dispersion spectrum (EDAX) as shown in Figure 4. It shows that $\mathrm{C}, \mathrm{N}, \mathrm{O}, \mathrm{Si}$, and $\mathrm{S}$ peaks were obtained with the atomic ratios $(\%)$ of $19.69,9.81,53.65$, 16.14 , and 0.71 , respectively. Therefore, it is assumed that Met was carefully conjugated on the surface of $\mathrm{MSN}-\mathrm{NH}_{2}$ by epiclon as the cross linker.

The incorporation of organic moieties was further confirmed by TGA of MSNs (Figure 5). Results showed that MSN-FA and MSN-Met lost up to $17.18 \%$ and $17.80 \%$ of their total mass at $800^{\circ} \mathrm{C}$, while $\mathrm{MSN}-\mathrm{NH}_{2}$ only lost up to $15.16 \%$ of its mass at the same temperature. These analyses confirm the higher carbon contents of folate and Met-modified silica than that of MSN-NH$H_{2}$. The difference in weight loss between MSN-FA and MSN-Met with MSN-NH can be attributed to decomposable folic acid and Met-epiclon groups, respectively. Based on TGA results, the calculated

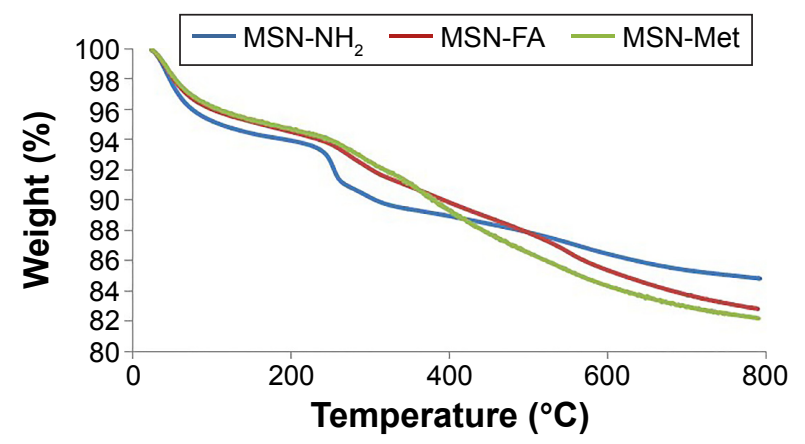

Figure 5 TGA curves for MSN-NH${ }_{2}$, MSN-FA, and MSN-Met.

Abbreviations: TGA, thermogravimetric analysis; MSN, mesoporous silica nanoparticle; FA, folic acid; Met, methionine. molar organic contents of folate and Met-epiclon are about $0.0457 \mathrm{~mol} / \mathrm{g}$ and $0.0474 \mathrm{~mol} / \mathrm{g}$, respectively.

\section{DTX loading and release}

Previous studies showed that MSNs tend to have a high loading capacity, but low-loaded drug amounts are obtained for poorly water-soluble and large molecule drugs. ${ }^{40,50-53}$ However, in this study, the large-pore MSNs caused high pay loading of DTX. ${ }^{41,42}$ The drug-loading amounts of DTX in MSN-NH, MSN-FA, and MSN-Met are shown in Table 1, which increased compared to the prior studies. ${ }^{54}$ Higher loading of DTX into MSN-NH ${ }_{2}$ and MSN-FA pores is related to the strong electrostatic attraction between the negative charge of DTX and the positive charge of MSNs surface. The zeta potential of MSN-NH $\mathrm{N}_{2}$ and MSN-FA was found to be positive, but MSN-Met has shown negative zeta potential. Another possible reason for this phenomena (lower loading of DTX into MSN-Met) could be due to the steric hindrance of the epiclon-Met on the surfaces of MSNs resulting in acting as a band for entrance of DTX. ${ }^{55,56}$ In addition, the in vitro release profiles of DTX from MSNs under different $\mathrm{pH}$ conditions were drawn as shown in Figure 6. All MSNs showed a pH-dependent DTX release pattern in the buffer medium in neutral and acidic $\mathrm{pH}$. Hence, amine groups at inner pore surfaces led to controlled and $\mathrm{pH}$-sensitive release of the DTX molecules by electrostatic attraction. Considering the fact that the tumor tissues are more acidic than the normal tissues, the ideal $\mathrm{pH}$ sensitive system is the one in which drugs are hardly released in normal tissues and consequently inhibit toxic side effects but can be released in tumor tissues or cancer cells to the enhancement of drug efficiency.

\section{Intracellular uptake}

MSN cellular uptake and accumulation after exposure of MCF-7 cells to MSNs-FITC were indicated by flow cytometry (FCM) results. Figure 7 shows the more affinity of MCF-7 cells to the MSNs-FITC in comparison with free FITC as negative control $(1.4 \% \pm 0.3 \%$ intracellular uptake).

Table I Loading efficiency percentage and loading capacity percentage of MSN-NH${ }_{2}$, MSN-FA, and MSN-Met with DTX

\begin{tabular}{|c|c|c|}
\hline Nanoparticles & $\begin{array}{l}\text { Loading } \\
\text { efficiency (\%) }\end{array}$ & $\begin{array}{l}\text { Loading } \\
\text { capacity (\%) }\end{array}$ \\
\hline MSN-NH ${ }_{2}$ & $20.8 I \pm 2.33$ & $7.68 \pm 0.32$ \\
\hline MSN-FA & $18.19 \pm 2.74$ & $6.78 \pm 0.33$ \\
\hline MSN-Met & $9.78 \pm 1.81$ & $3.77 \pm 0.28$ \\
\hline
\end{tabular}

Note: Data presented as mean \pm standard deviation.

Abbreviations: MSN, mesoporous silica nanoparticle; FA, folic acid; Met, methionine; DTX, docetaxel. 


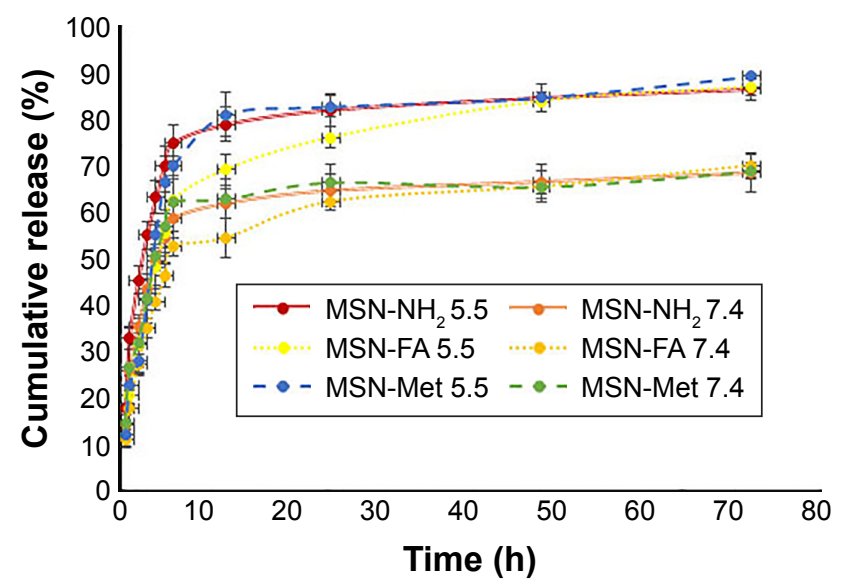

Figure 6 In vitro DTX release profiles from MSN-NH, MSN-FA, and MSN-Met. Note: Results are expressed at $\mathrm{pH}=5.5$ and $7.4,37^{\circ} \mathrm{C}(\mathrm{n}=3)$.

Abbreviations: DTX, docetaxel; MSN, mesoporous silica nanoparticle; FA, folic acid; Met, methionine; h, hours.
FCM studies on MCF-7 cells showed an $8.3 \% \pm 0.09 \%$ intracellular uptake for MSN-NH${ }_{2}$, but high intracellular uptake ratios of $23.2 \% \pm 1.7 \%$ and $79.3 \% \pm 1.9 \%$ were obtained for MSN-Met and MSN-FA, respectively. These outcomes indicated that the higher affinity of MCF-7 cells to targeted MSNs than $\mathrm{MSN}_{-} \mathrm{NH}_{2}$. On the other hand, these results corroborate the better cell viability of MSN-FA in MCF-7 cells than of other MSNs, which is confirmed by the half maximal inhibitory concentration $\left(\mathrm{IC}_{50}\right)$ results. According to the past studies, it seems that the cellular uptake of the MSNs may happen through macro pinocytosis. ${ }^{57-59}$ However, the exact mechanism of cellular uptake of MSNs is not completely clear and requires more research. The comparison of MSNs uptake in MCF-7 cells demonstrated that, although MCF-7 cells express a much higher level of LAT1, LAT2, and FA

B

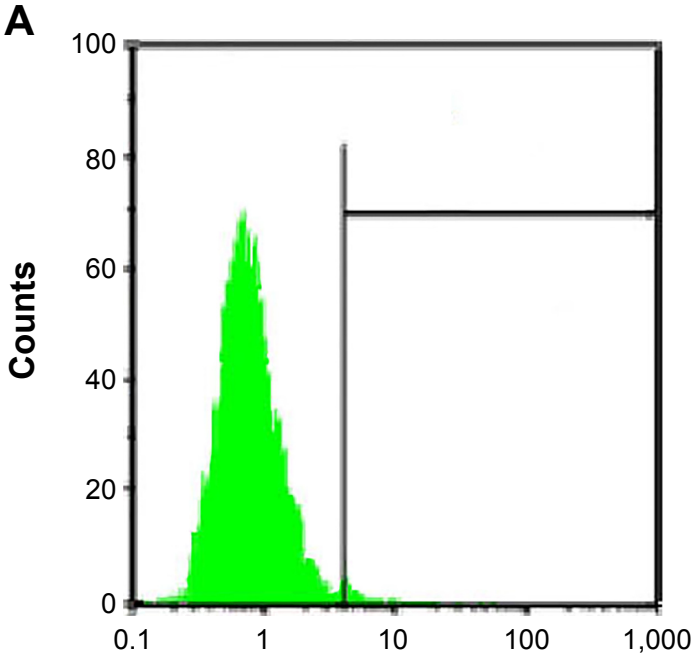

FL1

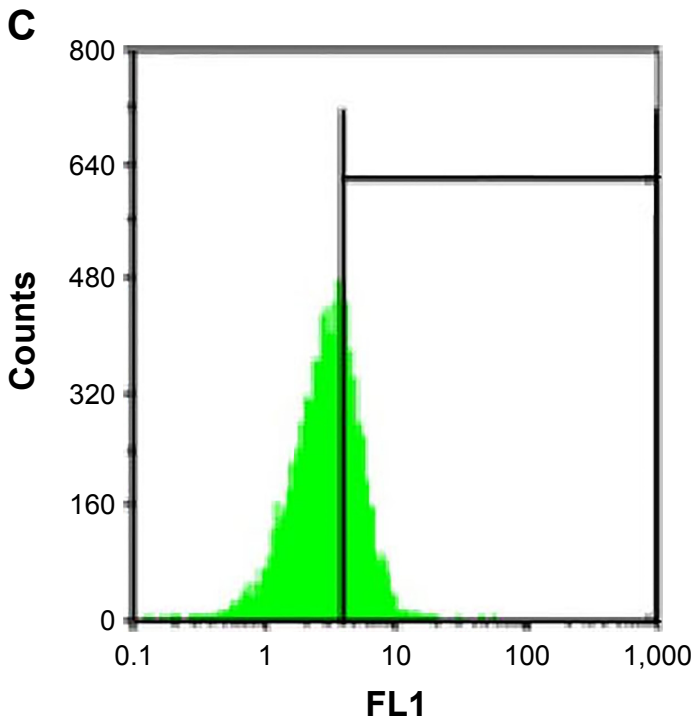

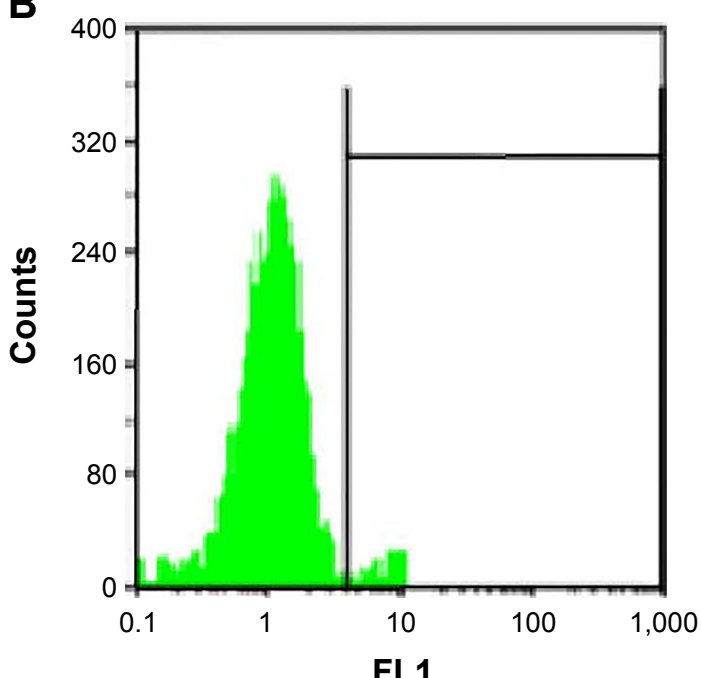

FL1

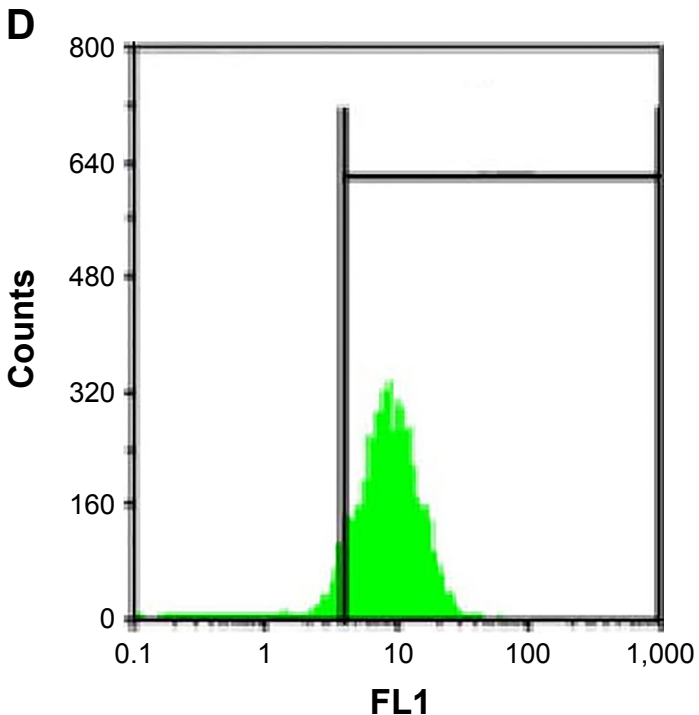

Figure 7 Fluorescent intensity of (A) free FITC, (B) MSN-NH, (C) MSN-FA, and (D) MSN-Met in MCF-7 cells analyzed by FACS.

Abbreviations: FITC, fluorescein isothiocyanate; MSN, mesoporous silica nanoparticle; FA, folic acid; Met, methionine; FACS, fluorescence-activated cell sorting. FL, logarithm of fluorescence intensity. 
receptors, they internalized much more targeted MSNs (MSNMet and MSN-FA) compared to MSN-NH ${ }_{2}$. Consequently, the uptake of MSNs can be enhanced by using folic acid and Met as targeting ligands, and data confirm the important role of the targeting moiety. ${ }^{60-63}$ These observations suggest that the intracellular uptake of MSN-Met and MSN-FA was more targetspecific. Figure 7 shows that MSN-FA intracellular uptake in MCF-7 was higher than that found in MSN-Met. Further, it can be deduced that the uptake of MSN-FA in MCF-7 cells was 3-4 times higher than the MSN-Met uptake and 9-10 times more efficient than MSN-NH . This indicates efficient uptake of the MSN-FA for breast cancer cells. Moreover, the results confirm that the MSN-FA was cell permeable, indicating a potential application in intracellular drug delivery.

\section{Inhibitory effect against tumor cells}

MTT assay was used to evaluate the cytotoxicity. DTX/ MSNs cytotoxicity compared with free DTX at equivalent concentrations is shown in Figure 8. After 24 hours, 48 hours and 72 hours of exposure, DTX-loaded MSNs exhibited dose-dependent cytotoxicity. All the DTX/MSN types exhibited significantly more cytotoxic effect than free DTX in all mentioned incubation times. The poor solubility of DTX may limit its internalization into cells, but the uptake of MSNs may lead to the more efficient DTX accumulation and higher cytotoxicity of DTX/MSNs. MTT assay results at different time periods indicate that pretreatment with free DTX and DTX/MSNs will cause lower cell viability at longer incubation period. Targeted DTX/MSNs were more cytotoxic compared to DTX/MSN-NH ${ }_{2}$, and DTX/MSN-FA toxicity was higher than DTX/MSN-Met. The MTT assay results show that targeted DTX/MSNs increased cytotoxicity and DTX/MSN-FA was more successful, which was confirmed by uptake and apoptosis outcomes. As shown in Table 2, the obtained $\mathrm{IC}_{50}$ results show no significant cytotoxicity after 24 hours of treatment of blank MSN-NH 2 , MSN-Met, and MSN-FA on MCF-7 cells. It can be concluded that MSNs are biocompatible carriers and play no role in toxicity in MCF-7 cells. ${ }^{64,65}$ Overall, results attest to the potential of DTX/MSNs for DTX delivery by increasing the effectiveness of targeted delivery.
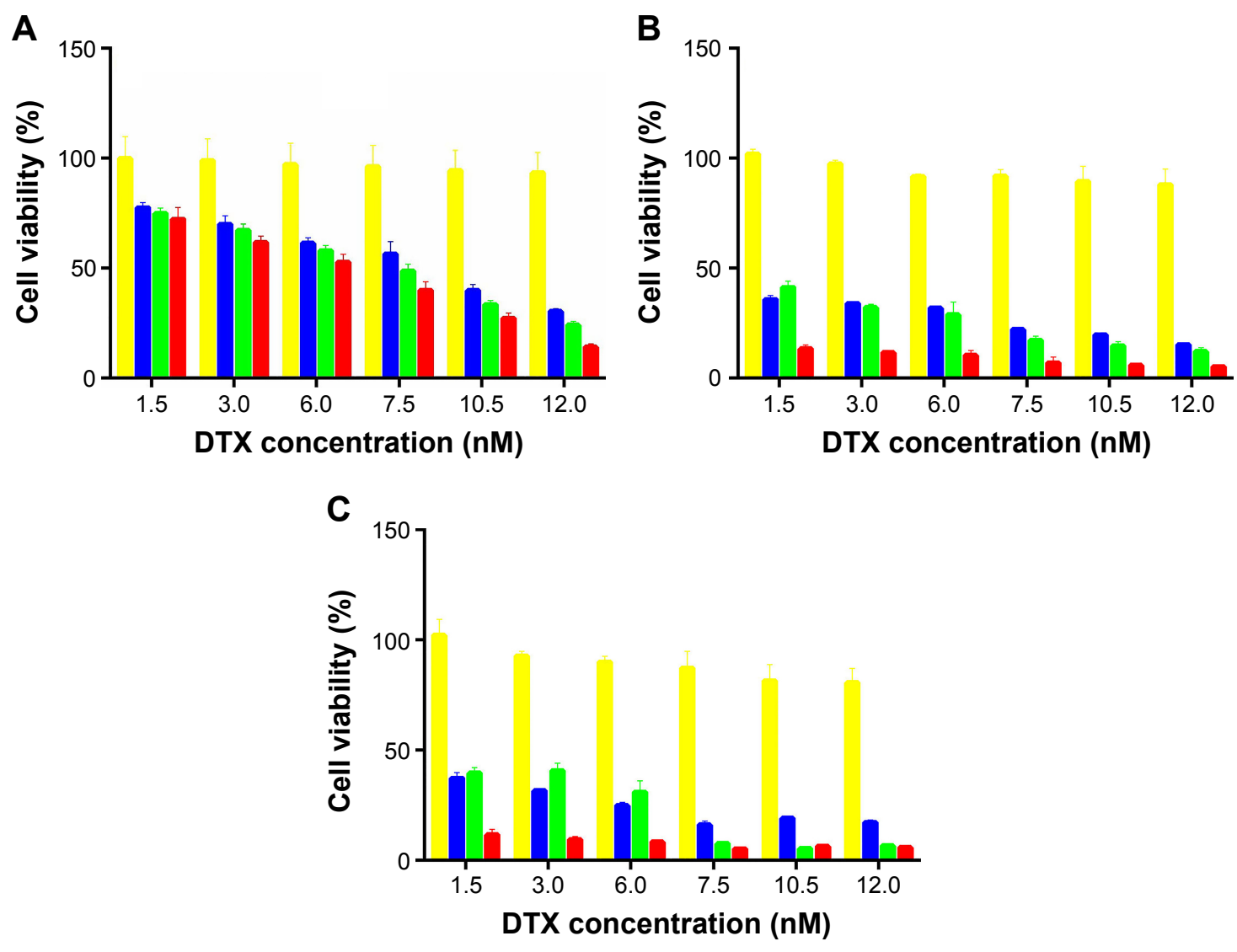

DTX MSN-NH$_{2} \square$ MSN-FA

Figure 8 Cytotoxicity of DTX/MSN-NH , DTX/MSN-Met and DTX/MSN-FA compared to free DTX against MCF-7 cells after treatment for (A) 24 hours, (B) 48 hours, and (C) 72 hours. Data represent mean $\pm S D(n=3)$.

Abbreviations: DTX, docetaxel; MSN, mesoporous silica nanoparticle; Met, methionine; FA, folic acid; SD, standard deviation. 
Table 2 Outcomes for $\mathrm{IC}_{50}$ calculations based on the linear model

\begin{tabular}{ll}
\hline Nanoparticles & IC $_{50}(\mathbf{n M})$ \\
\hline MSN-NH & $12,335 \pm 356.27$ \\
MSN-FA & $12,890 \pm 499.11$ \\
MSN-Met & $12,564 \pm 217.20$ \\
DTX/MSN-NH & $2,14 \pm 0.62$ \\
DTX/MSN-FA & $5.72 \pm 0.58$ \\
DTX/MSN-Met & $6.99 \pm 0.27$ \\
Free DTX & $81.85 \pm 7.51$ \\
\hline
\end{tabular}

Note: Data represent mean $\pm S D(n=3)$.

Abbreviations: MSN, mesoporous silica nanoparticle; FA, folic acid; Met, methionine; DTX, docetaxel; SD, standard deviation; $\mathrm{IC}_{50}$, half maximal inhibitory concentration.

\section{Death mechanisms of MCF-7 cells}

The death mechanisms of MCF-7 cells treated with the DTX/MSN-NH ${ }_{2}$, DTX/MSN-Met, and DTX/MSN-FA nanoparticles and free DTX for 24 hours were evaluated by FCM and FACS protocols (Figure 9). Early apoptosis was
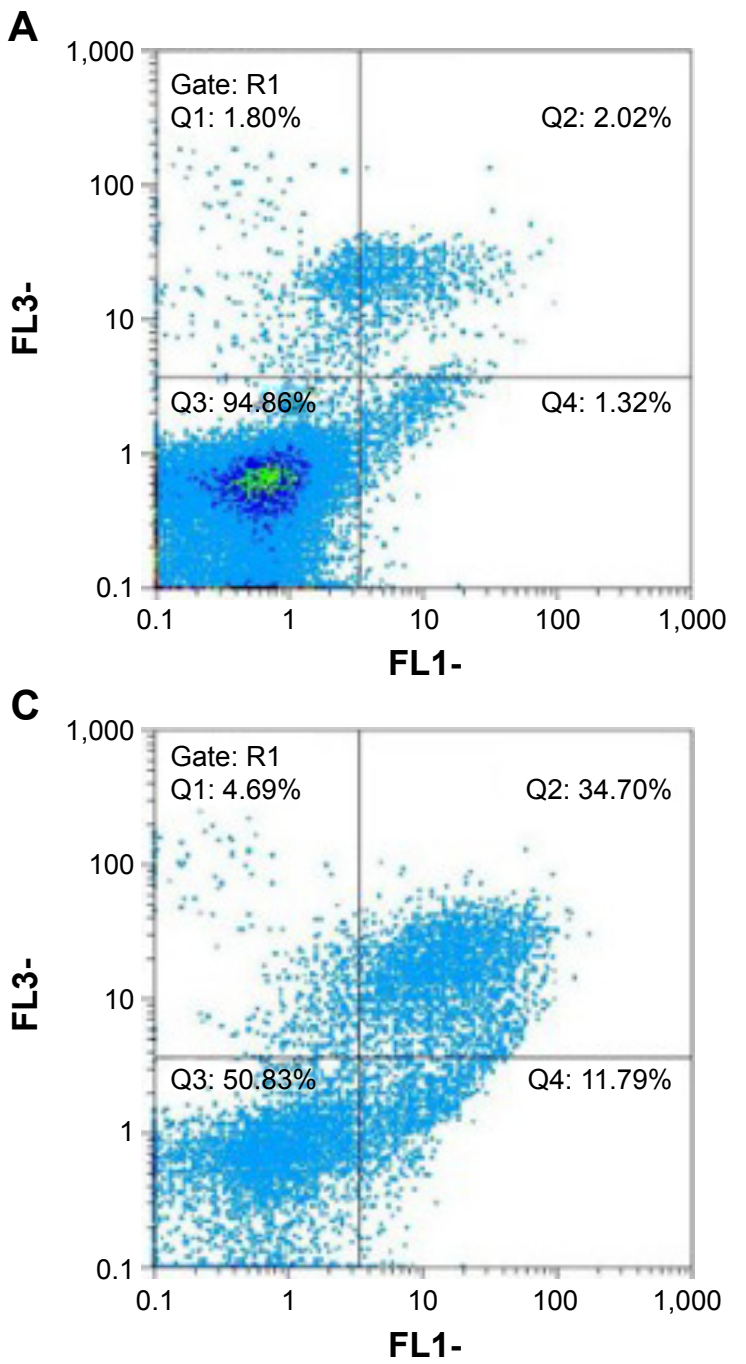

induced in $4.46 \%, 11.79 \%$, and $14.13 \%$ of the MCF-7 cells after treatment with the DTX/MSN-NH ${ }_{2}$, DTX/MSN-Met, and DTX/MSN-FA nanoparticles, respectively. Treatment with DTX had a slight influence on the MCF-7 cells and induced early apoptosis in $1.32 \%$ of the cells, which could be attributed to the poor internalization of DTX into cells. Treatment of MCF-7 cells with the DTX/MSN-NH ${ }_{2}$, DTX/MSNMet, and DTX/MSN-FA nanoparticles and free DTX induced late apoptosis and necrosis in $20.52 \%, 3.39 \%, 56.99 \%$, and $3.82 \%$ of the cells, respectively. The free DTX shows very little influence on the apoptosis and necrosis of MCF-7 cells than other DTX-loaded nanoparticles. However, DTX/MSN samples with the same DTX concentration could simultaneously induce distinct early and late apoptosis of MCF-7 cells in 1 day (Figure 9). DTX/MSNs could induce more late apoptosis of MCF-7 cells than early apoptosis. Com-
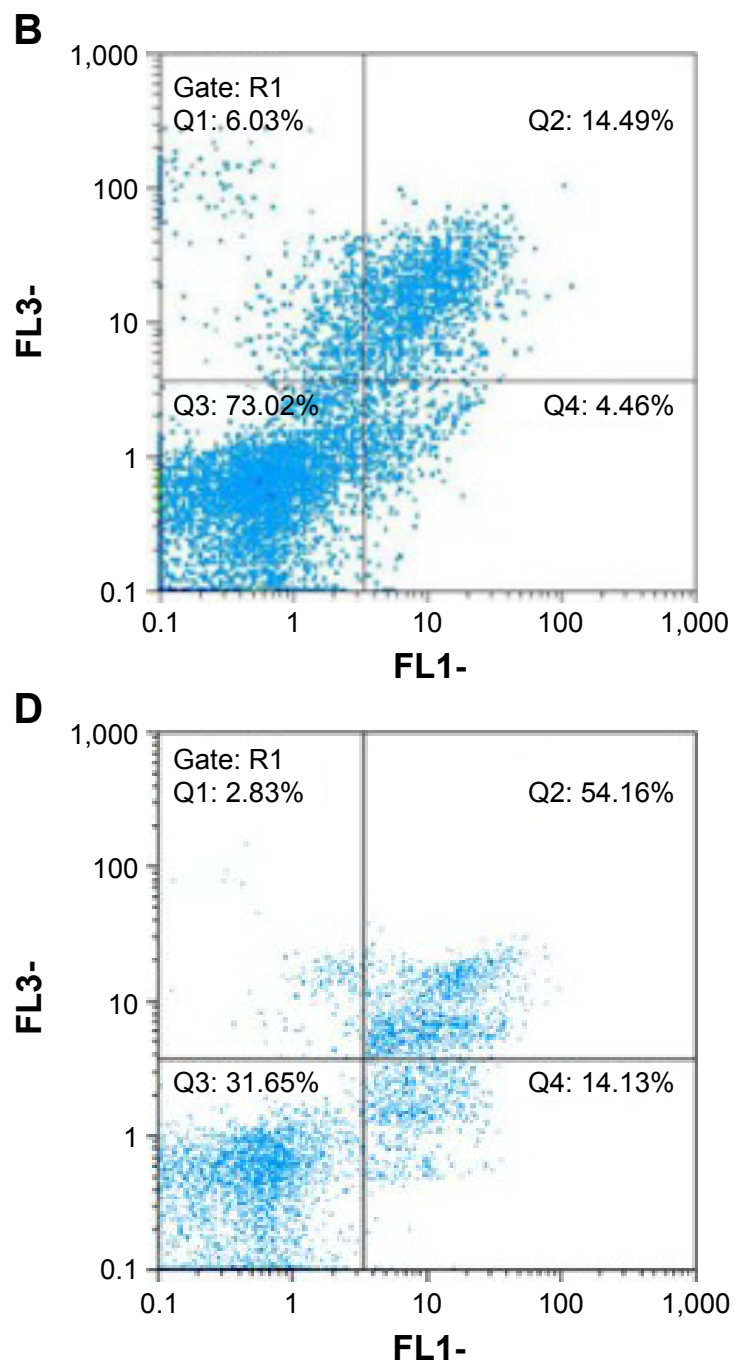

Figure 9 Evaluation of the death mechanisms for MCF-7 cells treated with (A) DTX, (B) DTX/MSN-NH ${ }_{2}$, (C) DTX/MSN-Met, and (D) DTX/MSN-FA for I day by FCM and FACS protocols.

Abbreviations: DTX, docetaxel; MSN, mesoporous silica nanoparticle; Met, methionine; FA, folic acid; FCM, flow cytometry; FACS, fluorescence-activated cell sorting; FL, logarithm of fluorescence intensity. 
Table 3 The percentages of the different types of cell deaths induced by DTX, DTX/MSN-NH ${ }_{2}$, DTX/MSN-Met, and DTX/ MSN-FA as observed by FCM

\begin{tabular}{|c|c|c|c|c|}
\hline $\begin{array}{l}\text { Cell type } \\
\text { concentration }\end{array}$ & DTX & MSN-NH ${ }_{2}$ & MSN-FA & MSN-Met \\
\hline & & & & \\
\hline $\begin{array}{l}\text { Early apoptotic } \\
\text { cells (\%) }\end{array}$ & & & & $15.20 \pm 1.34$ \\
\hline $\begin{array}{l}\text { Late apoptotic } \\
\text { cells (\%) }\end{array}$ & $2.32 \pm 0.42$ & $|4.8| \pm 1.49$ & $34.91 \pm 3.08$ & $52.42 \pm 1.22$ \\
\hline Necrotic cells (\%) & $2.03 \pm 0.34$ & $5.82 \pm 1.87$ & $4.33 \pm 0.40$ & $2.74 \pm 0.44$ \\
\hline
\end{tabular}

Note: Data presented as mean \pm standard deviation $(n=3)$.

Abbreviations: DTX, docetaxel; MSN, mesoporous silica nanoparticle; Met, methionine; FA, folic acid; FCM, flow cytometry.

pared with DTX/MSNs, DTX/MSN-FA remarkably would induce early and late apoptosis of MCF-7 cells at the same particle concentrations, and DTX/MSN-Met showed higher early and late apoptotic cells than DTX/MSN-NH, which is also dependent on the target group as showed in previous studies. ${ }^{24,66}$ To sum up, DTX/MSNs could induce MCF-7 cell apoptosis by a synergistic apoptosis effect, which could be attributed to an enhancement of DTX uptake with synergistic effects of target groups by MCF-7 cells (Table 3).

\section{In vivo distribution of nanoparticles}

For in vivo biodistribution analyses, first biodistribution behaviors of all MSNs were evaluated in healthy BALB/c mice by Kodak in vivo imaging system. At the next stage,
NIR fluorescence images of ex vivo organs were obtained from scarified BALB/c mice 2 hours after injection. The biodistribution behavior of $\mathrm{MSN}-\mathrm{NH}_{2}, \mathrm{MSN}-\mathrm{Met}$, and MSN-FA at equal concentrations ( $1 \mathrm{mg} / 0.1 \mathrm{~mL}$ ) was assessed to compare the effect of the target-directed folic acid and Met agents for active targeted delivery, with $\mathrm{MSN}-\mathrm{NH}_{2}$ as a passive delivery agent. A single dose of FITC-MSNs and PBS as the control group was injected within the heart in triple groups. Figure 10 displays the NIR fluorescence images of the healthy BALB/c mice at prescheduled time points after the injection of FITC-MSNs. The images show that the highest accumulation time point was 2 hours after injection. As shown in Figure 10, 2 hours after the administration of FITC-MSNs in healthy BALB/c mice, more MSN-NH ${ }_{2}$ were accumulated in the liver, but MSN-Met and MSN-FA were more observed in the kidney as confirmed by ex vivo results. At the best intensity time point of treatment, the animals were scarified in order to observe nanoparticle distributions. This examination was performed on both healthy and tumor-induced mice. Fluorescence intensities of ex vivo organs were measured by Kodak Molecular Imaging Software 5.X for image analysis. Organs and tumor-induced tissues that take different FITC-MSNs amounts are displayed in Figure 11. Among healthy BALB/c mice organs, higher accumulations of MSNs were accumulated in the lung, liver, and kidney than in other organs. Notably among tumorinduced $\mathrm{BALB} / \mathrm{c}$ mice organs and tumor tissues, the highest

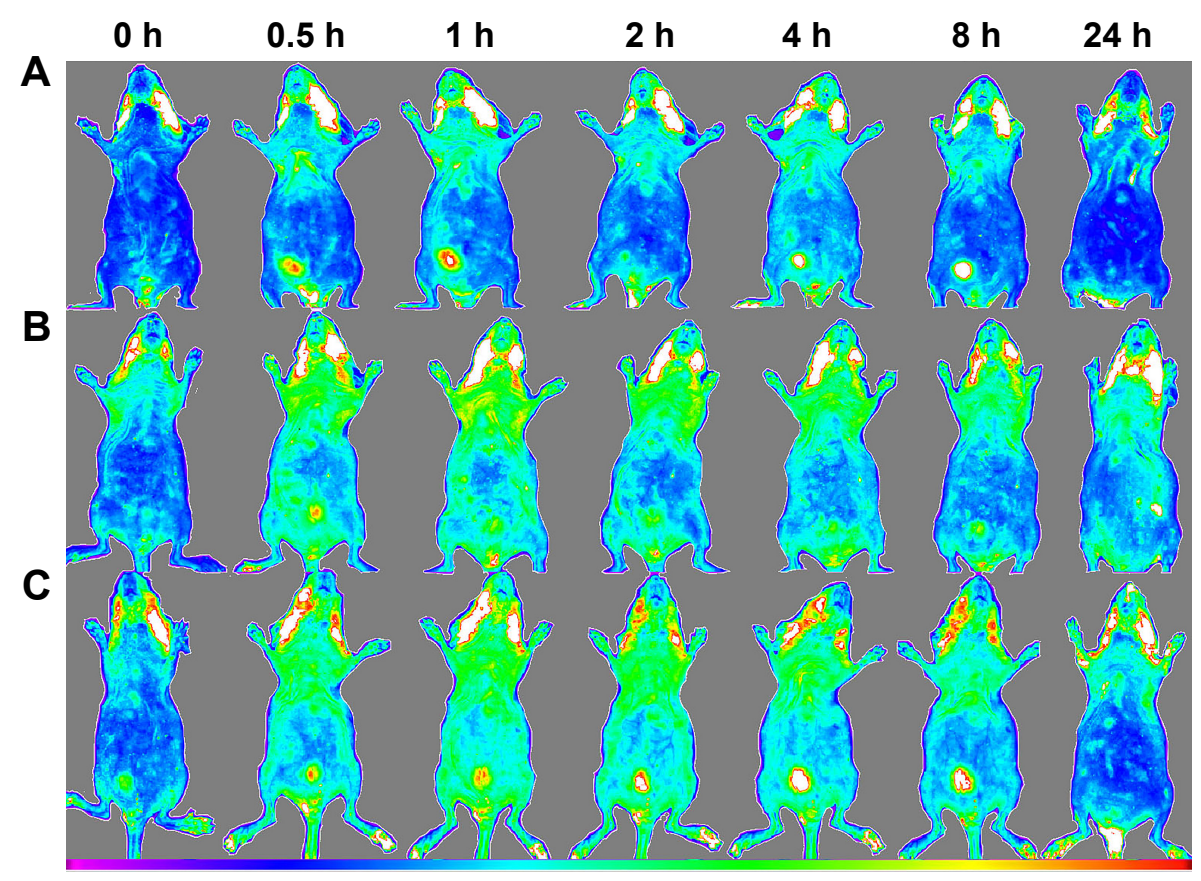

Figure 10 In vivo fluorescence imaging of healthy BALB/c mice after injection of $(\mathbf{A}) \mathrm{MSN}_{\mathrm{N}} \mathrm{NH}_{2}$, (B) MSN-FA, and (C) MSN-Met ( $\mathrm{n}=3$ ). Abbreviations: MSN, mesoporous silica nanoparticle; FA, folic acid; Met, methionine; h, hours. 


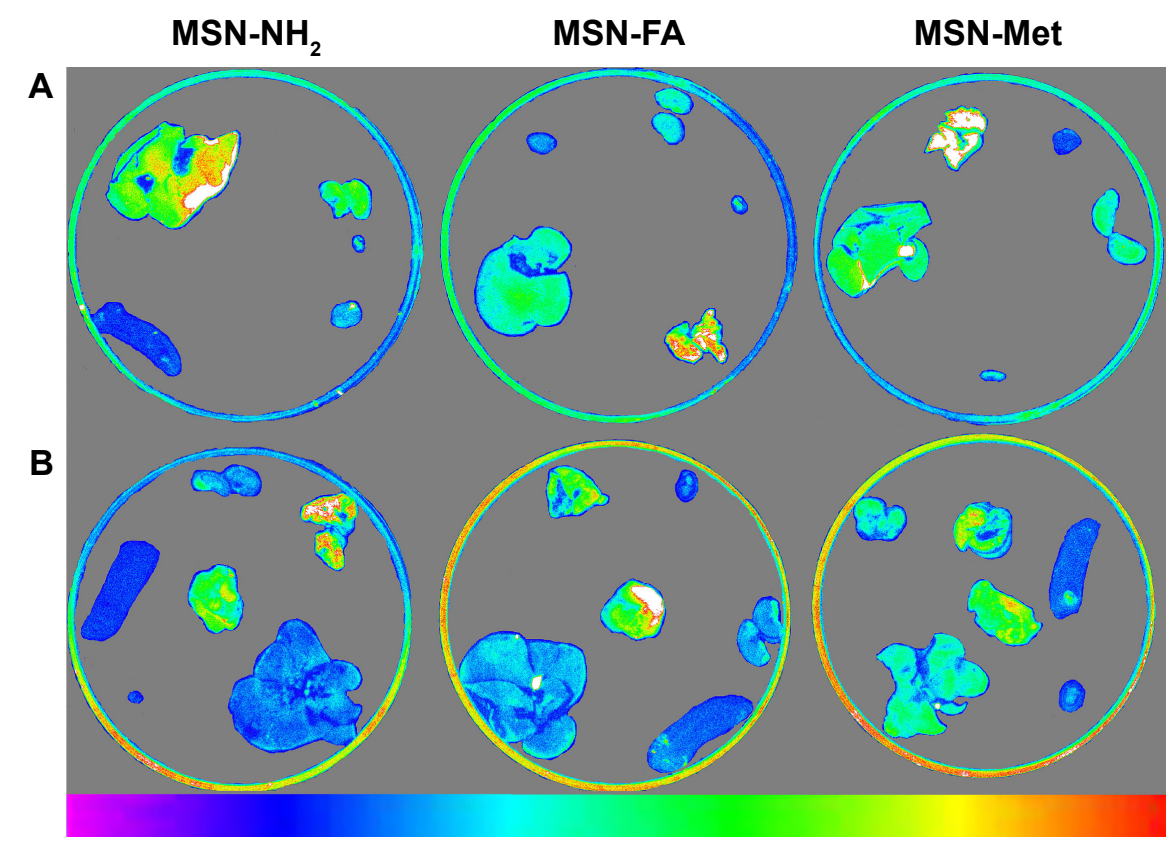

Figure II Images of dissected organs of (A) healthy and (B) tumor-induced BALB/c mice after injection of MSN-NH$H_{2}$, MSN-FA, or MSN-Met $(n=3)$. Abbreviations: MSN, mesoporous silica nanoparticle; FA, folic acid; Met, methionine.

fluorescence intensities of all FITC-MSNs were seen in the tumor tissues. Additionally, $\mathrm{MSN}-\mathrm{NH}_{2}$ accumulation in the liver was much higher than that in the kidney. Conversely, targeted MSNs were more accumulated in the kidney than in the liver. This can be related to renal execration trends of targeted MSNs by surface modification. ${ }^{66}$

The accumulations of MSNs in different organs were analyzed by calculating the mean fluorescence intensities. As plotted in Figure 12A and B, the most accumulated organ for all MSNs was the lung, whereas the accumulation of MSNs decreased in the liver, kidney, spleen, and heart, respectively. However, targeted MSNs had a tendency to be present more in the kidney that has less metabolic action than in the liver. Moreover, obviously higher fluorescence was observed in the tumor tissue compared with other tissues and fluorescence intensity in the tumor tissue was relatively high in MSN-FA $(P<0.05)$. Higher accumulation of all MSNs in tumor tissues with high permeability completely confirmed passive targeted delivery by nanoparticles. ${ }^{67,68}$ On the other hand, folic acid modification on to the surface of the MSNs induced an efficient delivery, and this is while MSN-Met accumulation in tumor tissues was relatively small, which suggests folic acid as a suitable targeting agent for active target-directed delivery. $39,69,70$
A

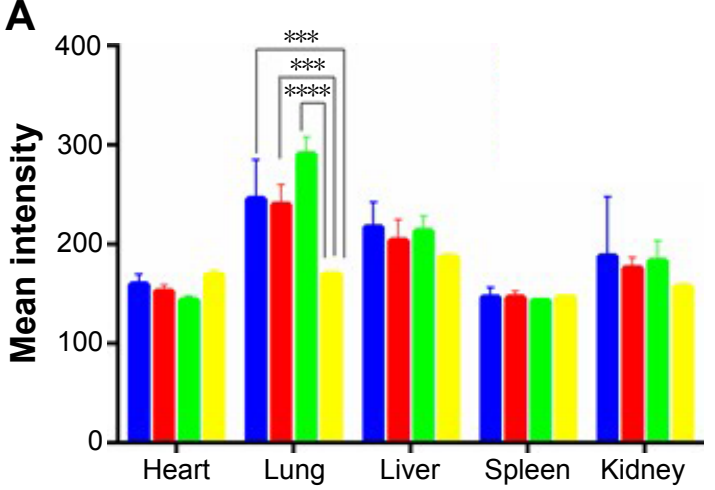

B

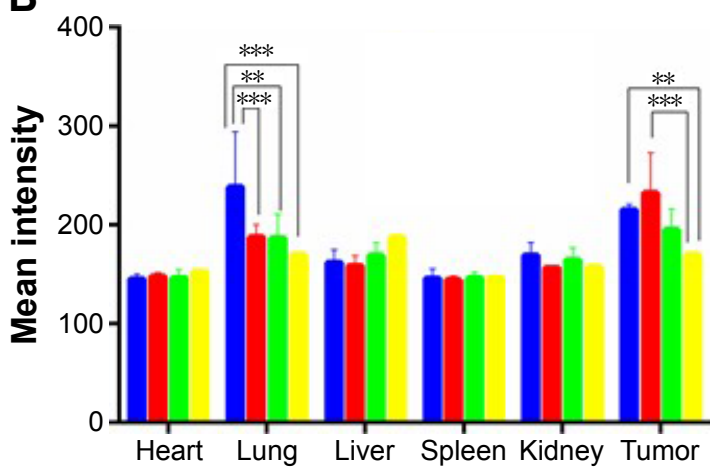

MSN-NH ${ }_{2}=$ MSN-FA MSN-Met PBS

Figure 12 Biodistribution of MSN-NH,$~ M S N-F A$, and MSN-Met in (A) healthy and (B) tumor-induced BALB/c mice 2 hours following injection. Notes: Obtained data were calculated as percentages of mean intensity and represented as mean $\pm S D(n=3)$. $* * P<0.05 ; * * * P<0.01 ; * * * * P<0.00 I$. Abbreviations: MSN, mesoporous silica nanoparticle; FA, folic acid; Met, methionine; PBS, phosphate-buffered saline; SD, standard deviation. 


\section{Conclusion}

Functionalized and DTX-loaded MSNs (DTX/MSN-NH, DTX/MSN-Met, and DTX/MSN-FA) that were designed in this study have a high drug-loading capacity and $\mathrm{pH}$-sensitive drug release kinetic. The examination of cytotoxicity and cell death mechanisms shows that cytotoxicity of targeted nanoparticles increased and more apoptosis and necrosis occurred. Biodistribution behavior by ex vivo fluorescent imaging on sacrificed tumor-induced BALB/c mice attested to the accumulation of MSNs in tumor tissues, which confirmed the targeting ability of MSN-FA compared with that of MSN-Met and MSN-NH${ }_{2}$. Overall, the results showed that DTX/MSN-FA exhibited enhanced target-directed drug delivery for breast cancer, which can cause a decrease in dose, raise cytotoxic effects and efficiently repress cancer cells. In conclusion, DTX/MSN-FA exhibited enhanced antitumor efficacy, which makes them promising substances for cancer therapy.

\section{Acknowledgment}

This work was supported by a grant from Tehran University of Medical Sciences (grant number 92-02-33-21635).

\section{Disclosure}

The authors report no conflicts of interest in this work.

\section{References}

1. Ferlay J, Shin HR, Bray F, Forman D, Mathers C, Parkin DM. Estimates of worldwide burden of cancer in 2008: GLOBOCAN 2008. Int J Cancer. 2010;127(12):2893-2917.

2. Jemal A, Center MM, DeSantis C, Ward EM. Global patterns of cancer incidence and mortality rates and trends. Cancer Epidemiol Biomarkers Prev. 2010;19(8):1893-1907.

3. Page R, Takimoto C. Principles of chemotherapy. Cancer Management: A Multidisciplinary Approach: Medical, Surgical, and Radiation Oncology. New York: PRP; 2004:21-38.

4. Ullah MF. Cancer multidrug resistance (MDR): a major impediment to effective chemotherapy. Asian Pac J Cancer Prev. 2008;9(1):1-6.

5. Peer D, Karp JM, Hong S, FaroKHzad OC, Margalit R, Langer R. Nanocarriers as an emerging platform for cancer therapy. Nat Nanotechnol. 2007;2(12):751-760.

6. Lianos GD, Vlachos K, Zoras O, Katsios C, Cho WC, Roukos DH. Potential of antibody-drug conjugates and novel therapeutics in breast cancer management. Onco Targets Ther. 2014;7:491-500.

7. Antony A. The biological chemistry of folate receptors. Blood. 1992; 79(11):2807-2820.

8. Garinchesa P, Campbell I, Saigo PE, Lewis JL, Old LJ, Rettig WJ. Trophoblast and ovarian-cancer antigen-Lk26 - sensitivity and specificity in immunopathology and molecular-identification as a folate-binding protein. Am J Pathol. 1993;142(2):557-567.

9. Meier R, Henning TD, Boddington S, et al. Breast cancers: MR imaging of folate-receptor expression with the folate-specific nanoparticle P1133. Radiology. 2010;255(2):527-535.

10. Zhang J, Rana S, Srivastava RS, Misra RDK. On the chemical synthesis and drug delivery response of folate receptor-activated, polyethylene glycol-functionalized magnetite nanoparticles. Acta Biomater. 2008; 4(1):40-48.
11. Montenegro M, González-Guerrero R, Sánchez-Del-Campo L, PiñeroMadrona A, Cabezas-Herrera J, Rodríguez-López J. Targeting the epigenetics of the DNA damage response in breast cancer. Cell Death Dis. 2016;7(4):e2180.

12. Mecham JO, Rowitch D, Wallace CD, Stern PH, Hoffman RM. The metabolic defect of methionine dependence occurs frequently in human tumor cell lines. Biochem Biophys Res Commun. 1983;117(2):429-434.

13. Zang X-P, Palwai NR, Lerner MR, Brackett DJ, Pento JT, Harrison RG. Targeting a methioninase-containing fusion protein to breast cancer urokinase receptors inhibits growth and migration. Anticancer Res. 2006; 26(3A):1745-1751.

14. Benavides MA, Oelschlager DK, Zhang HG, et al. Methionine inhibits cellular growth dependent on the p53 status of cells. Am J Surg. 2007; 193(2):274-283.

15. Halpern BC, Clark BR, Hardy DN, Halpern RM, Smith RA. The effect of replacement of methionine by homocystine on survival of malignant and normal adult mammalian cells in culture. Proc Natl Acad Sci USA. 1974;71(4):1133-1136.

16. Yoon JH, Kim IJ, Kim H, et al. Amino acid transport system L is differently expressed in human normal oral keratinocytes and human oral cancer cells. Cancer Lett. 2005;222(2):237-245.

17. Hyde R, Taylor PM, Hundal HS. Amino acid transporters: roles in amino acid sensing and signalling in animal cells. Biochem J. 2003;373: $1-18$.

18. McConathy J, Goodman MM. Non-natural amino acids for tumor imaging using positron emission tomography and single photon emission computed tomography. Cancer Metastasis Rev. 2008;27(4): $555-573$.

19. Omoomi FD, Siadat SD, Nourmohammadi Z, et al. Molecular chlorambucil-methionine conjugate: novel anti-cancer agent against breast MCF-7 cell model. J Cancer Sci Ther. 2013;5:75-84.

20. del Amo EM, Urtti A, Yliperttula M. Pharmacokinetic role of L-type amino acid transporters LAT1 and LAT2. Eur J Pharm Sci. 2008;35(3): 161-174.

21. Fuchs BC, Bode BP. Amino acid transporters ASCT2 and LAT1 in cancer: partners in crime? Semin Cancer Biol. 2005;15(4):254-266.

22. Raghavan V, Vijayaraghavalu S, Peetla C, Yamada M, Morisada M, Labhasetwar V. Sustained epigenetic drug delivery depletes cholesterolsphingomyelin rafts from resistant breast cancer cells, influencing biophysical characteristics of membrane lipids. Langmuir. 2015;31(42): 11564-11573.

23. Baker J, Ajani J, Scotté F, et al. Docetaxel-related side effects and their management. Eur J Oncol Nurs. 2009;13(1):49-59.

24. He Q, Gao Y, Zhang L, et al. A pH-responsive mesoporous silica nanoparticles-based multi-drug delivery system for overcoming multidrug resistance. Biomaterials. 2011;32(30):7711-7720.

25. He Q, Zhang J, Chen F, Guo L, Zhu Z, Shi J. An anti-ROS/hepatic fibrosis drug delivery system based on salvianolic acid B loaded mesoporous silica nanoparticles. Biomaterials. 2010;31(30):7785-7796.

26. Gan Q, Lu XY, Yuan YA, et al. A magnetic, reversible pH-responsive nanogated ensemble based on $\mathrm{Fe} 3 \mathrm{O} 4$ nanoparticles-capped mesoporous silica. Biomaterials. 2011;32(7):1932-1942.

27. Slowing II, Vivero-Escoto JL, Wu CW, Lin VSY. Mesoporous silica nanoparticles as controlled release drug delivery and gene transfection carriers. Adv Drug Deliv Rev. 2008;60(11):1278-1288.

28. Yang MH, Li H, Javadi A, Gong SQ. Multifunctional mesoporous silica nanoparticles as labels for the preparation of ultrasensitive electrochemical immunosensors. Biomaterials. 2010;31(12):3281-3286.

29. Sweetman CS. Martindale: The Complete Drug Reference. London: Pharmaceutical Press; 2009:662.

30. Missailidis S. Anticancer Therapeutics. Chichester: Wiley; 2008:80.

31. Yamamoto Y, Kawano I, Iwase H. Nab-paclitaxel for the treatment of breast cancer: efficacy, safety, and approval. Onco Targets Ther. 2011;4: 123-136.

32. Rashidi L, Vasheghani-Farahani E, Rostami K, Ganji F, Fallahpour M. Mesoporous silica nanoparticles with different pore sizes for delivery of pH-sensitive gallic acid. Asia Pac J Chem Eng. 2014;9(6):845-853. 
33. Tabasi O, Falamaki C, Khalaj Z. Functionalized mesoporous silicon for targeted-drug-delivery. Colloids Surf B Biointerfaces. 2012;98: $18-25$.

34. Shen ZY, Li Y, Kohama K, Oneill B, Bi JX. Improved drug targeting of cancer cells by utilizing actively targetable folic acid-conjugated albumin nanospheres. Pharmacol Res. 2011;63(1):51-58.

35. Rothberg KG, Ying YS, Kolhouse JF, Kamen BA, Anderson RGW. The glycophospholipid-linked folate receptor internalizes folate without entering the clathrin-coated pit endocytic pathway. J Cell Biol. 1990; 110(3):637-649.

36. Mallakpour S, Kowsari E. Synthesis and characterization of new optically active poly(amide-imide)s containing epiclone and L-methionine moieties in the main chain. Polym Adv Technol. 2005;16(10):732-737.

37. Mehravi B, Ardestani MS, Damercheli M, et al. Breast cancer cells imaging by targeting methionine transporters with gadolinium-based nanoprobe. Mol Imaging Biol. 2014;16(4):519-528.

38. Goodarzi N, Ghahremani MH, Amini M, et al. CD44-targeted docetaxel conjugate for cancer cells and cancer stem-like cells: a novel hyaluronic acid-based drug delivery system. Chem Biol Drug Des. 2014;83(6) 741-752.

39. Tavassolian F, Kamalinia G, Rouhani H, et al. Targeted poly(1- $\gamma$ glutamyl glutamine) nanoparticles of docetaxel against folate overexpressed breast cancer cells. Int J Pharm. 2014;467(1):123-138.

40. Gao Y, Chen Y, Ji X, et al. Controlled intracellular release of doxorubicin in multidrug-resistant cancer cells by tuning the shell-pore sizes of mesoporous silica nanoparticles. ACS Nano. 2011;5(12):9788-9798.

41. Sanchez-Moreno P, Boulaiz H, Ortega-Vinuesa JL, Peula-Garcia JM, Aranega A. Novel drug delivery system based on docetaxel-loaded nanocapsules as a therapeutic strategy against breast cancer cells Int J Mol Sci. 2012;13(4):4906-4919.

42. Morse DL, Gray H, Payne CM, Gillies RJ. Docetaxel induces cell death through mitotic catastrophe in human breast cancer cells. Mol Cancer Ther. 2005;4(10):1495-1504.

43. Hernández-Vargas H, Palacios J, Moreno-Bueno G. Molecular profiling of docetaxel cytotoxicity in breast cancer cells: uncoupling of aberrant mitosis and apoptosis. Oncogene. 2007;26(20):2902-2913.

44. Tang HY, Guo J, Sun Y, Chang BS, Ren QG, Yang WL. Facile synthesis of $\mathrm{pH}$ sensitive polymer-coated mesoporous silica nanoparticles and their application in drug delivery. Int J Pharm. 2011;421(2):388-396.

45. Tao K, Fang M, Alroy J, Sahagian GG. Imagable 4T1 model for the study of late stage breast cancer. BMC Cancer. 2008;8(1):1.

46. He H, Xiao H, Kuang H, et al. Synthesis of mesoporous silica nanoparticle-oxaliplatin conjugates for improved anticancer drug delivery. Colloids Surf B Biointerfaces. 2014;117:75-81.

47. Bootz A, Vogel V, Schubert D, Kreuter J. Comparison of scanning electron microscopy, dynamic light scattering and analytical ultracentrifugation for the sizing of poly (butyl cyanoacrylate) nanoparticles. Eur J Pharm Biopharm. 2004;57(2):369-375.

48. Fissan H, Ristig S, Kaminski H, Asbach C, Epple M. Comparison of different characterization methods for nanoparticle dispersions before and after aerosolization. Anal Methods. 2014;6(18):7324-7334.

49. Hoffmann F, Cornelius M, Morell J, Fröba M. Silica-based mesoporous organic-inorganic hybrid materials. Angew Chem Int Ed. 2006; 45(20):3216-3251.

50. Knežević NŽ, Durand J-O. Large pore mesoporous silica nanomaterials for application in delivery of biomolecules. Nanoscale. 2015; 7(6):2199-2209.

51. Liu Q, Zhang J, Sun W, Xie QR, Xia W, Gu H. Delivering hydrophilic and hydrophobic chemotherapeutics simultaneously by magnetic mesoporous silica nanoparticles to inhibit cancer cells. Int J Nanomedicine. 2012;7:999-1013.
52. Fan J, Fang G, Wang X, Zeng F, Xiang Y, Wu S. Targeted anticancer prodrug with mesoporous silica nanoparticles as vehicles. Nanotechnology. 2011;22(45):455102.

53. He Q, Shi J. Mesoporous silica nanoparticle based nano drug delivery systems: synthesis, controlled drug release and delivery, pharmacokinetics and biocompatibility. J Mater Chem. 2011;21(16):5845-5855.

54. Wang D, Huang J, Wang X, et al. The eradication of breast cancer cells and stem cells by 8-hydroxyquinoline-loaded hyaluronan modified mesoporous silica nanoparticle-supported lipid bilayers containing docetaxel. Biomaterials. 2013;34(31):7662-7673.

55. Malfanti A, Miletto I, Bottinelli E, et al. Delivery of gemcitabine prodrugs employing mesoporous silica nanoparticles. Molecules. 2016;21(4):522.

56. Mohamadnia Z, Ahmadi E, Ghasemnejad M, Hashemikia S, Doustgani A. Surface modification of mesoporous nanosilica with [3-(2-aminoethylamino) propyl] trimethoxysilane and its application in drug delivery. Int J Nanosci Nanotechnol. 2015;11(3):167-177.

57. Heidegger S, Göß1 D, Schmidt A, et al. Immune response to functionalized mesoporous silica nanoparticles for targeted drug delivery. Nanoscale. 2016;8(2):938-948.

58. Huang X, Teng X, Chen D, Tang F, He J. The effect of the shape of mesoporous silica nanoparticles on cellular uptake and cell function. Biomaterials. 2010;31(3):438-448.

59. Sahoo B, Devi KSP, Sahu SK, et al. Facile preparation of multifunctional hollow silica nanoparticles and their cancer specific targeting effect. Biomater Sci. 2013;1(6):647-657.

60. Chen Y, Cao J, Zhu H, et al. Synthesis and evaluation of methionine and folate co-decorated chitosan self-assembly polymeric micelles as a potential hydrophobic drug-delivery system. Chin Sci Bull. 2013;58(19): 2379-2386.

61. Mamaeva V, Rosenholm JM, Bate-Eya LT, et al. Mesoporous silica nanoparticles as drug delivery systems for targeted inhibition of Notch signaling in cancer. Mol Ther. 2011;19(8):1538-1546.

62. Petros RA, DeSimone JM. Strategies in the design of nanoparticles for therapeutic applications. Nat Rev Drug Discov. 2010;9(8):615-627.

63. Senthilkumar R, Karaman DŞ, Paul P, et al. Targeted delivery of a novel anticancer compound anisomelic acid using chitosan-coated porous silica nanorods for enhancing the apoptotic effect. Biomater Sci. 2015;3(1):103-111.

64. Menon N, Leong DT. Cytotoxic effects of phosphonate-functionalised mesoporous silica nanoparticles. ACS Appl Mater Interfaces. 2016;8(3): 2416-2422.

65. Rosenholm JM, Mamaeva V, Sahlgren C, Lindén M. Nanoparticles in targeted cancer therapy: mesoporous silica nanoparticles entering preclinical development stage. Nanomedicine. 2012;7(1):111-120.

66. He Q, Zhang Z, Gao F, Li Y, Shi J. In vivo biodistribution and urinary excretion of mesoporous silica nanoparticles: effects of particle size and PEGylation. Small. 2011;7(2):271-280.

67. Guo X, Shi C, Wang J, Di S, Zhou S. pH-triggered intracellular release from actively targeting polymer micelles. Biomaterials. 2013; 34(18):4544-4554.

68. Xie M, Xu Y, Shen H, Shen S, Ge Y, Xie J. Negative-charge-functionalized mesoporous silica nanoparticles as drug vehicles targeting hepatocellular carcinoma. Int J Pharm. 2014;474(1):223-231.

69. Lu J, Li Z, Zink JI, Tamanoi F. In vivo tumor suppression efficacy of mesoporous silica nanoparticles-based drug-delivery system: enhanced efficacy by folate modification. Nanomedicine. 2012;8(2):212-220.

70. Lu J, Liong M, Li Z, Zink JI, Tamanoi F. Biocompatibility, biodistribution, and drug-delivery efficiency of mesoporous silica nanoparticles for cancer therapy in animals. Small. 2010;6(16):1794-1805. 


\section{Publish your work in this journal}

OncoTargets and Therapy is an international, peer-reviewed, open access journal focusing on the pathological basis of all cancers, potential targets for therapy and treatment protocols employed to improve the management of cancer patients. The journal also focuses on the impact of management programs and new therapeutic agents and protocols on

patient perspectives such as quality of life, adherence and satisfaction. The manuscript management system is completely online and includes a very quick and fair peer-review system, which is all easy to use. Visit http://www.dovepress.com/testimonials.php to read real quotes from published authors.

Submit your manuscript here: http://www.dovepress.com/oncotargets-and-therapy-journal 